\title{
Key Performance Indicators for PVT Systems
}

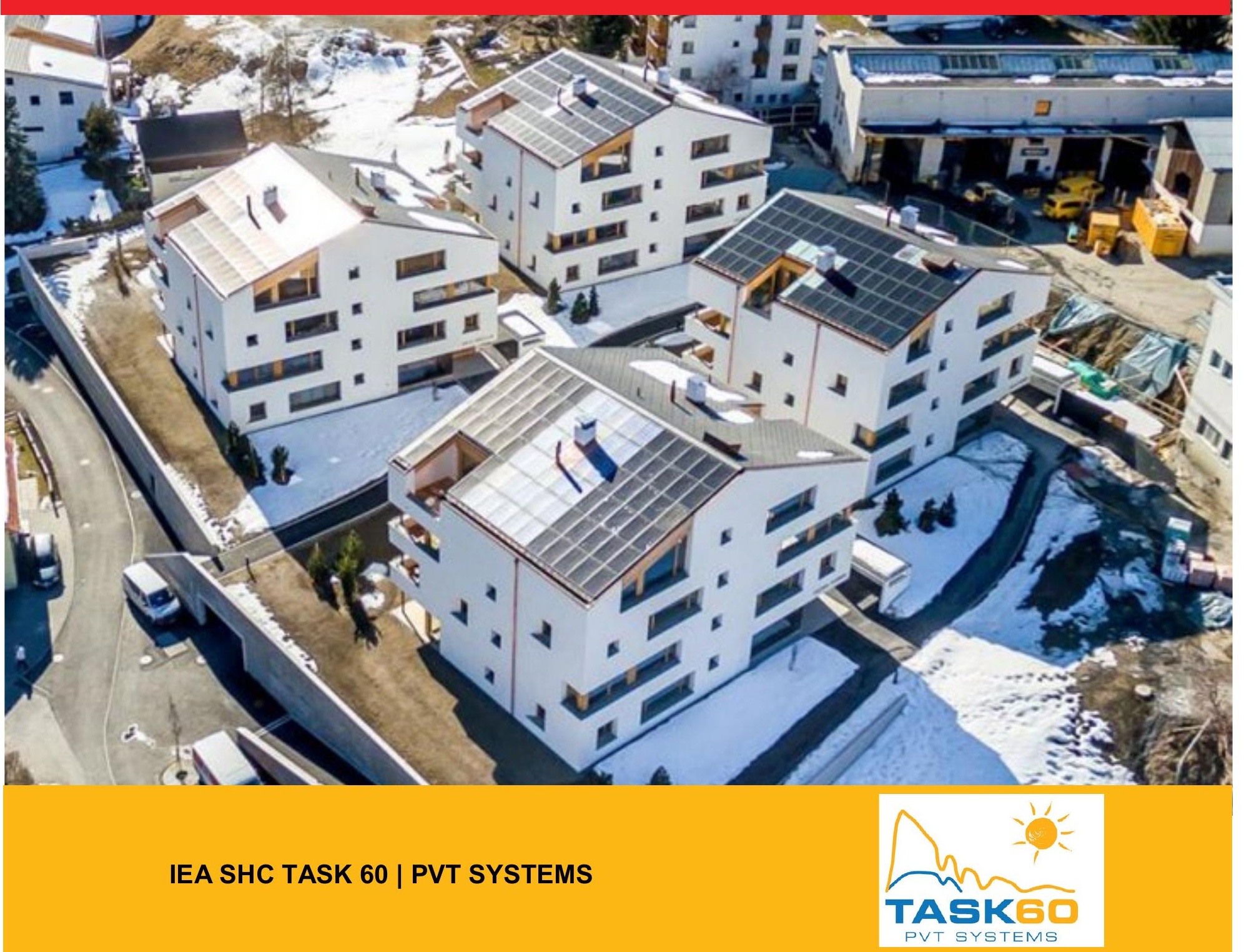



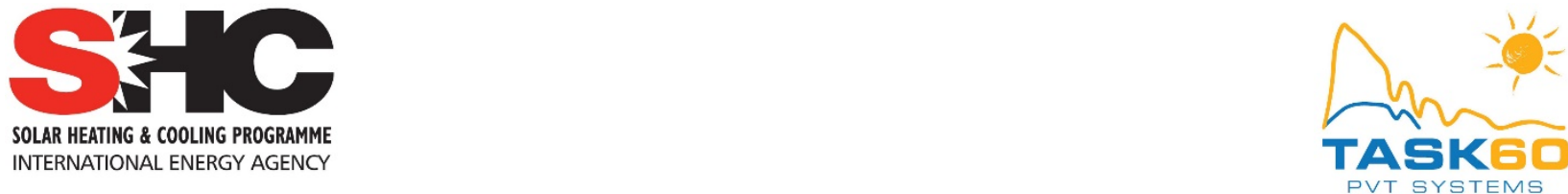

\section{Key Performance Indicators for PVT Systems}

\section{SHC Task 60/Report D1}

Main author: Daniel Zenhäusern, SPF Institute for Solar Technology, OST University of Applied Sciences, Rapperswil, Switzerland

With contributions by (in alphabetical order):

Antonio Gagliano (University of Catania), Danny Jonas (University of Saarbrücken), Giuseppe Marco Tina (University of Catania), Jean-Christophe Hadorn, Manuel Lämmle (Fraunhofer ISE), María Herrando (University of Zaragoza)

Date: November $8^{\text {th }}, 2020$

Report number: D1

DOI: 10.18777/ieashc-task60-2020-0007 


\section{IEA Solar Heating and Cooling Technology Collaboration Programme (IEA SHC)}

The Solar Heating and Cooling Technology Collaboration Programme was founded in 1977 as one of the first multilateral technology initiatives ("Implementing Agreements") of the International Energy Agency. Its mission is "To enhance collective knowledge and application of solar heating and cooling through international collaboration to reach the goal set in the vision of solar thermal energy meeting 50\% of low temperature heating and cooling demand by 2050."

The members of the IEA SHC collaborate on projects (referred to as Tasks) in the field of research, development, demonstration (RD\&D), and test methods for solar thermal energy and solar buildings.

Research topics and the associated Tasks in parenthesis include:

- Solar Space Heating and Water Heating (Tasks 14, 19, 26, 44, 54)

- Solar Cooling (Tasks 25, 38, 48, 53)

- Solar Heat for Industrial or Agricultural Processes (Tasks 29, 33, 49, 62, 64)

- Solar District Heating (Tasks 7, 45, 55)

- Solar Buildings/Architecture/Urban Planning (Tasks 8, 11, 12, 13, 20, 22, 23, 28, 37, 40, 41, 47, 51, 52, 56, 59, 63)

- Solar Thermal \& PV (Tasks 16,35,60)

- Daylighting/Lighting (Tasks 21, 31, 50, 61)

- Materials/Components for Solar Heating and Cooling (Tasks 2, 3, 6, 10, 18, 27, 39)

- Standards, Certification, and Test Methods (Tasks 14, 24, 34, 43, 57)

- $\quad$ Resource Assessment (Tasks 1, 4, 5, 9, 17, 36, 46)

- Storage of Solar Heat (Tasks 7, 32, 42, 58)

In addition to our Task work, other activities of the IEA SHC include our:

$>$ International Conference on Solar Heating and Cooling for Buildings and Industry

$>$ SHC Solar Academy

> Solar Heat Worldwide annual statics report

> Collaboration with solar thermal trade associations

\section{Country Members}

$\begin{array}{lll}\text { Australia } & \text { France } & \text { South Africa } \\ \text { Austria } & \text { Germany } & \text { Spain } \\ \text { Belgium } & \text { Italy } & \text { Sweden } \\ \text { Canada } & \text { Netherlands } & \text { Switzerland } \\ \text { China } & \text { Norway } & \text { Turkey } \\ \text { Denmark } & \text { Portugal } & \text { United Kingdom } \\ \text { European Commission } & \text { Slovakia } & \end{array}$

\section{Sponsor Members}

European Copper Institute

ECREEE

International Solar Energy Society PCREEE

CCREEE

RCREEE

EACREEE

SACREEE 


\section{Contents}

\section{Contents}

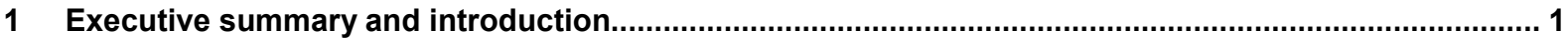

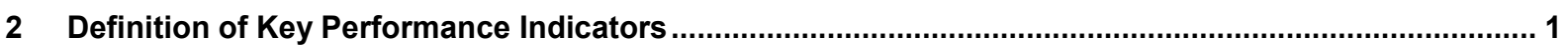

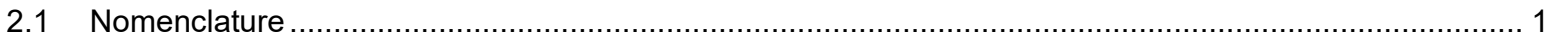

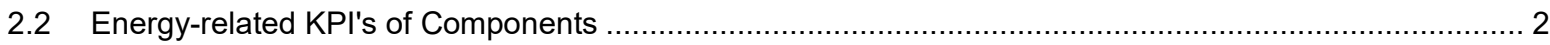

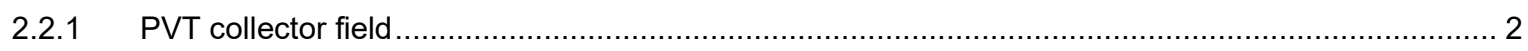

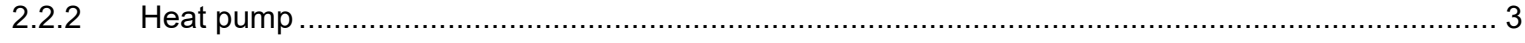

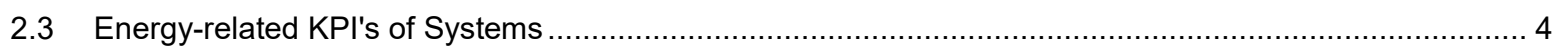

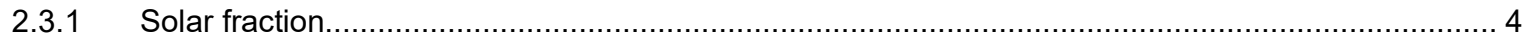

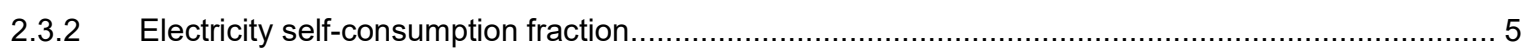

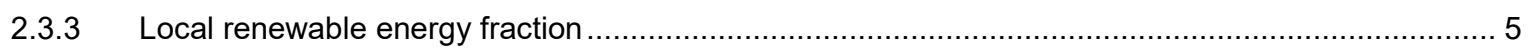

2.3.4 Performance factor of a solar and heat pump system and fractional electricity savings ................. 6

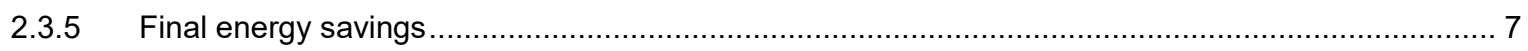

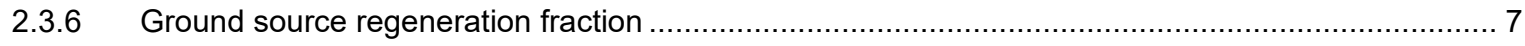

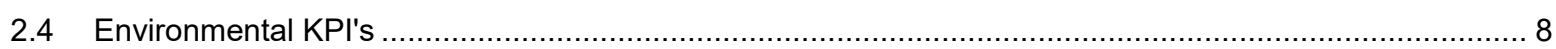

2.4.1 Non-renewable primary energy factor and savings........................................................ 8

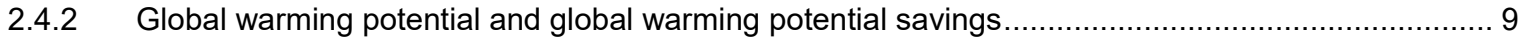

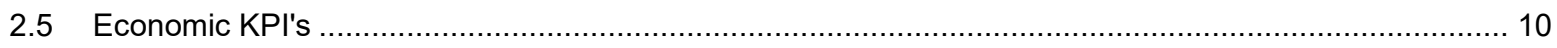

3 Application example 1 - Comparison of three buildings of the building complex Sotchà.................... 12

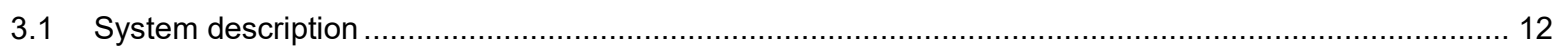

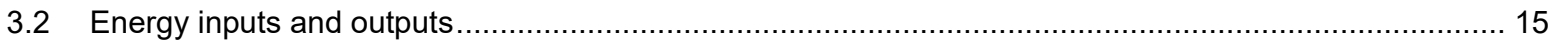

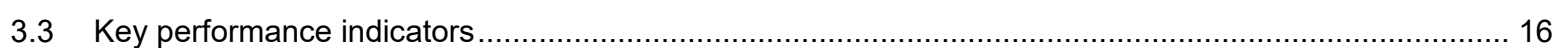

4 Application example 2 - Simulation study comparing PVT \& PV with Thermal collectors \& PV .......... 24

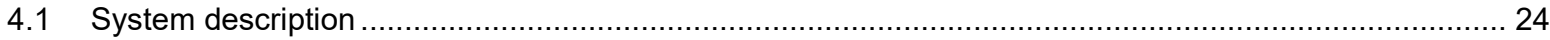

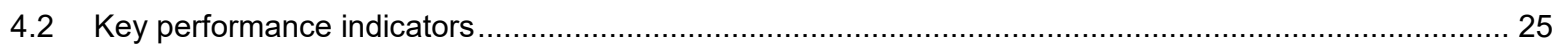

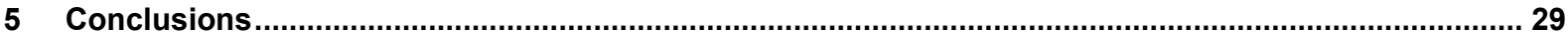

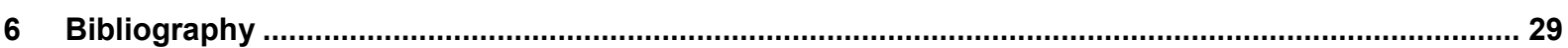




\section{Executive summary and introduction}

In order to judge the performance of a technology, well-defined Key Performance Indicators (KPI's) are needed. Such indicators are for instance used to quantitatively compare different components or systems, or, as another example, in order to quantify the impact of optimisation steps on a component or a system. KPI's can be applied both to measurement data and to data generated by mathematical simulation in the component or system design phase.

The aim of this report is to provide precise definitions of useful KPl's for PVT systems. Where possible, these definitions correspond to those used in the technology fields of solar thermal systems and photovoltaic systems. In particular, the KPI's for the thermal performance of PVT systems are to a considerable extent based on the definitions adopted in IEA SHC Task 44 (Hadorn 2015). The stipulation and use of standardized KPI's and notations will be essential for the comparability of different research results.

The KPI's presented here are mainly intended for assessing the performance of PVT systems in field operation or simulated systems, e.g. in the system design phase. Some of the KPI's assess a particular component of the system and others the whole system. In particular, for a given project or location, the KPI's will be useful to compare system solutions based on PVT with solutions based on other technologies. The intended purpose of the presented KPI's is not, however, the assessment and comparison of PVT collector products in standard laboratory testing conditions. For this topic, the reader is referred to Subtask B report B1 "Status Quo of PVT Characterization".

The used nomenclature and the KPI definitions are provided in section 2. This is followed by two application examples for the KPl's. The first example, presented in section 3, is the comparison of measurement data of three equivalent buildings that are equipped with three different solar energy systems. In the second example, section 4 , KPI's are applied to simulation results, in order to compare the performance of the combinations PV \& covered PVT and PV \& thermal collectors for the case of a multi-family building.

In the separate report D2 "Performance Assessment of PVT Example Systems" a selection of the KPI's defined here is applied to a series of PVT systems in operation.

\section{Definition of Key Performance Indicators}

\subsection{Nomenclature}

Energy in the form of heat is denoted here by the letter $Q$, electrical energy by the letter $E$. A negative amount of heat ("cold") may be denoted by the letter $C$. A quantity of heat, cold, or electricity that flows from a component $A$ to a component $B$ is denoted by $Q_{A, B}, C_{A, B}\left(=-Q_{B, A}\right)$, or $E_{A, B}$, respectively. An asterisk means the sum of all the heat or electrical energy that flows away from a component $A$ (e.g. $Q_{A, *}$ ) or to a component $B$ (e.g. $Q_{*, B}$ ). If the context permits it, the asterisk can be omitted. E.g. instead of $Q_{P V T, *}$, one may use $Q_{P V T}$ to denote all the heat that flows from the PVT collector field to the system, in cases where PVT collectors are not used for cooling purposes or rejecting heat. Similarly, the total electricity consumption of a component that doesn't itself produce electricity, like e.g. a heat pump, can be denoted as $E_{H P}$ instead of $E_{*, H P}$. Also other sub- and superscripts may be omitted, if the context allows it, in order to simplify the notations. Quantities representing a thermal or electrical power (energy flow rate) are denoted by $\dot{Q}$ or $\dot{E}$, respectively. The subscript "sys" can be used to bundle all system components of the heating or cooling system. E.g. $E_{P V T, s y s}$ stands for the total electrical energy delivered by the PVT field to the different system components (excluding batteries). ${ }^{1}$ Other subscripts can be defined when necessary. Global solar irradiation is denoted by $G$, with a subscript " $h$ " for irradiation on a horizontal surface and "col" for irradiation on the collector plane. In cases where energy losses that occur between components $A$ and $B$ (e.g. thermal losses of a pipe, or losses of electrical energy due to cable losses or a DC-to-DC converter) are relevant, one can specify by a superscript with parenthesis, if the quantity is determined at the component $A\left(Q_{A, B}^{(A)}\right)$ or $B\left(Q_{A, B}^{(B)}\right)$. Other superscripts can be used to further specify the quantities.

\footnotetext{
1 In systems with a battery, the battery is not included in sys. This means for instance that the total locally produced solar energy used by the heating and cooling system is $E_{P V T, s y s}+E_{B a t, s y s}$ (if the battery is only charged with solar electricity), where $E_{B a t, s y s}$ is the electricity going from the battery to the heating and cooling system components.
} 


\subsection{Energy-related KPI's of Components}

\subsubsection{PVT collector field}

The instantaneous thermal and electrical efficiencies of a PVT collector are defined as

$$
\begin{gathered}
\eta_{P V T, t h}^{\text {gross }}=\frac{\dot{Q}_{P V T}}{G_{c o l} \cdot A_{P V T}^{\text {gross }}}, \\
\eta_{P V T, \text { el }}^{D C, \text { gross }}=\frac{\dot{E}_{P V T}^{D C}}{G_{c o l} \cdot A_{P V T}^{\text {gross }}},
\end{gathered}
$$

related to the gross collector area $A_{P V T}^{\text {gross }}$, as defined in e.g. ISO 9488. Efficiencies may also be related to a different reference area, or, in the case of the electrical efficiency, given for AC instead of DC. The efficiencies depend on the conditions under which they are measured. Standard conditions for evaluating thermal efficiencies of collectors are e.g. defined in the standard ISO 9806 and for photovoltaic modules with crystalline silicon cells in EN 61215. The electrical efficiency at standard test conditions "STC", which can be found in product datasheets, can be written as $\eta_{P V T, \text { el }}^{D C, \text { gross }, S T C}=\frac{\dot{E}_{P V T}^{D C, S T C}}{1000 \mathrm{~W} / \mathrm{m}^{2} \cdot A_{P V T}^{g r o s s}}$.

The performance of a collector (field) over a specified time period can be quantified by means of the thermal and electrical utilisation ratios, ${ }^{2}$ [see e.g. the guideline VDI 6002 by the Association of German Engineers or (Hadorn 2015)].

$$
\begin{aligned}
\omega_{P V T, t h}^{\text {gross }} & =\frac{Q_{P V T}}{\int G_{\text {col }} d t \cdot A_{P V T}^{\text {gross }}}, \\
\omega_{P V T, \text { el }}^{D C, \text { gross }} & =\frac{E_{P V T}^{D C}}{\int G_{\text {col }} d t \cdot A_{P V T}^{g r o s s}},
\end{aligned}
$$

or, adding up the thermal and the electrical yield, by the energy utilisation ratio

$$
\omega_{P V T, \text { en }}^{D C, \text { gross }}=\frac{Q_{P V T}+E_{P V T}^{D C}}{\int G_{c o l} d t \cdot A_{P V T}^{g r o s s}} .
$$

A simple summing up of thermal and electrical energy as is done in the energy utilisation ratio doesn't account for the potentially different value of heat and electricity. There exist different options to account for this, however with the drawback of being less intuitive and involving some assumptions. One of the options is to define an exergy utilisation ratio, for which one would replace $Q_{P V T}$ by $\int d t\left(\dot{Q}_{P V T} \cdot \eta_{\text {Carnot }}\right)$ with the Carnot efficiency $\eta_{\text {Carnot }}=1-T_{\text {Sink }} / T_{m}$ computed with the mean fluid temperature in the collector field $T_{m}=\left(T_{\text {in }}+T_{\text {out }}\right) / 2$ and some sink temperature $T_{\operatorname{Sink}}$ to be specified. Another option would be to replace the generated electricity by an "equivalent amount of heat", which can for instance be done by multiplying the electrical energy by a constant factor $1 / \eta$. The choice of the value of $\eta$ is a matter of convention. A possible option would be to use the primary energy efficiency (related to primary energy input) of a conventional thermal power plant.

For the comparison of the utilisation ratios of PVT collector fields with other solar installations, like pure PV fields, solar thermal collector fields or side-by-side PV plus thermal collector fields, it is suggested to also define the analogue quantities with the subscripts "PV", "T" and "sol" instead of "PVT", where the quantities with the subscripts "PV" and "T" are related to the surface area of the respective component, i.e. PV or solar collector field, and those with "sol" are related to the complete surface area of the solar installation. For an installation combining different solar components (PVT and/or PV and/or T) one would hence define the following solar utilisation ratios

$$
\begin{gathered}
\omega_{\text {sol,th }}^{\text {gross }}=\frac{Q_{P V T}+Q_{T}}{\int G_{c o l} d t \cdot\left(A_{P V T}^{\text {gross }}+A_{P V}^{\text {gross }}+A_{T}^{\text {gross }}\right)}, \\
\omega_{\text {sol,el }}^{A C, \text { gross }}=\frac{E_{P V T}^{A C}+E_{P V}^{A C}}{\int G_{c o l} d t \cdot\left(A_{P V T}^{g r o s s}+A_{P V}^{\text {gross }}+A_{T}^{\text {gross }}\right)}, \\
\omega_{\text {sol,en }}^{A C, \text { gross }}=\frac{Q_{P V T}+Q_{T}+E_{P V T}^{A C}+E_{P V}^{A C}}{\int G_{c o l} d t \cdot\left(A_{P V T}^{\text {gross }}+A_{P V}^{g r o s s}+A_{T}^{\text {gross }}\right)} .
\end{gathered}
$$

\footnotetext{
2 In systems where collectors are operated below ambient temperature in order to collect ambient heat, $\eta_{t h}$ and $\omega_{t h}$ can take values $>1$ or grow infinite and their use may not make sense.
} 
Area-specific quantities like e.g. thermal and electrical yields which are also a frequently used performance indicator, can be denoted by lower case letters as $q_{P V T}^{\text {gross }}=Q_{P V T} / A_{P V T}^{\text {gross }}$ and $e_{P V T}^{D C \text {,gross }}=E_{P V T}^{D C} / A_{P V T}^{g r o s s}$.

Photovoltaic yields are often related to the nominal power. We can denote these quantities by the letter $Y$, common in PV literature, and define the nominal-power-related electrical yield as

$$
Y_{P V T}^{A C}=\frac{E_{P V T}^{A C}}{\dot{E}_{P V T}^{D C, S T C}} .
$$

Another quantity often used to characterise the performance of PV installations is the electrical performance ratio $\boldsymbol{P R}$, corresponding to the ratio between the actual AC electrical yield and the electrical yield that would have resulted if the modules had been operated at STC efficiency ${ }^{3}$. It is defined as

$$
P R_{P V T}=\frac{\frac{E_{P V T}^{A C}}{\dot{E}_{P V T}^{D C S T C}}}{\int \frac{G_{c o l} d t}{1000 W / m^{2}}}=\frac{E_{P V T}^{A C}}{\int G_{c o l} d t \cdot A_{P V T}^{g r o S S} \cdot \eta_{P V T, e l}^{D C, g r o S S, S T C}} .
$$

\subsubsection{Characteristic collector field temperature}

In order to assess the value of the heat provided by a PVT system, it is necessary to have an indication of the temperature levels at which the PVT system is operated. For this purpose, one can define a "characteristic temperature" of the collector field. Such an indicator allows to judge, for instance, whether the thermal and electrical yields of a PVT collector field are in the expected range for a certain type of collector and in a certain climate.

A simple option for defining a characteristic collector field temperature is the time average of the collector mean fluid temperature $\vartheta_{m}=\frac{\vartheta_{\text {in }}+\vartheta_{\text {out }}}{2}$ during operation

$$
\overline{\vartheta_{m}}=\frac{1}{\Delta t} \int_{\substack{\text { collector field } \\ \text { in operation }}} \vartheta_{m} d t
$$

where $\Delta t$ is the total time of operation. $\overline{\vartheta_{m}}$ considers only periods during which the collector field is in operation, i.e. during which the collector field circulation pump is active.

Another option is to define a characteristic temperature as the thermal-output-weighted average of the mean fluid temperature

$$
\vartheta_{\text {char,output }}^{m}=\frac{\int\left(\vartheta_{m} \cdot \dot{Q}_{P V T}\right) d t}{\int \dot{Q}_{P V T} d t} .
$$

Yet another option is to define a characteristic temperature as the irradiation-weighted average of the mean fluid temperature, as suggested and analysed in Ref. (Lämmle et al. 2017)

$$
\vartheta_{c h a r, G}^{m}=\frac{\int\left(\vartheta_{m} \cdot G_{c o l}\right) d t}{\int G_{c o l} d t} .
$$

A characteristic temperature is a simple indicator for the collector field operating conditions in units of temperature. It allows to assess the value of the produced heat, without referring to less intuitive thermodynamic concepts. For the comparison of different PVT installations, it is recommended to always provide a characteristic collector field temperature, thus allowing a consistent comparison of energy yields, achieved utilisation ratios, and other KPI's.

\subsubsection{Heat pump}

Since PVT collectors are often used in connection with a heat pump, e.g. as a low temperature heat source, we also include here the most relevant KPI's for this component. With the notation defined in Section 2.1, the instantaneous coefficient of performance (COP) of a heat pump is defined as

$$
C O P_{H P}=\frac{\dot{Q}_{H P, *}}{\dot{E}_{H P}} .
$$

\footnotetext{
${ }^{3}$ STC stands for the so-called Standard Test Conditions, i.e. an irradiance of $1000 \mathrm{~W} / \mathrm{m}^{2}$ with the reference solar spectrum according to the IEC standard 60904-3 and a PV cell temperature of $25^{\circ} \mathrm{C}$.
} 
In accordance with IEA-SHC Task 44 (Hadorn 2015), $Q_{H P, *}$ is determined at the connectors of the heat pump and $E_{H P}$ includes the electricity consumption for the compressor as well as for internal circulation pumps, fans and controls. For characterising the performance over a specified time period, it is common to use the heat pump performance factor, which relates the corresponding integrated quantities of provided heat and consumed electricity

$$
(S) P F_{H P}=\frac{Q_{H P, *}}{E_{H P}} \text {. }
$$

Following the definitions of Task 44, the subscript "HP+" is used, if the electricity consumption of the auxiliary components, like circulating pumps on the source and the sink side, etc. is also included. If the considered time period is a full year, one refers to the seasonal performance factor $S P F_{H P}$. Further, one can make use of superscripts $\left(E_{H P}^{(o n)}\right.$ and $\left.E_{H P}^{(o f f)}\right)$ for distinguishing between the electrical consumption during operation and during "stand-by", and, accordingly, define $P F_{H P}^{(o n)}=Q_{H P, *} / E_{H P}^{(o n)}$.

\subsection{Energy-related KPI's of Systems}

\subsubsection{Solar fraction}

The solar thermal fraction is the proportion of the heat input into the system, which is provided by solar thermal energy. In systems with a heat pump, only the direct solar heat, i.e. the part of the solar heat that is injected on the secondary side of the heat pump (typically to a heat storage tank), is counted. In different standards and publications one can find different definitions of the solar thermal fraction. Here, we use the following definition, which e.g. is used in VDI 6002-1,

$$
f_{\text {sol,th }}=\frac{Q_{P V T}^{(\text {direct })}}{Q_{a u x, *}+Q_{P V T}^{(\text {direct })}} .
$$

where $Q_{P V T}^{(\text {direct })}$ is the directly usable solar heat provided by the collector, typically heat injected to a heat storage tank (i.e. not counting solar heat used e.g. for ground source regeneration or as source heat of a heat pump), and $Q_{a u x, *}$ is the heat provided to the system by other heat sources (generators), like e.g. a gas burner or a heat pump.

In the case of solar and heat pump systems where the solar heat is primarily or entirely injected to the system on the primary side of the heat pump, the solar fraction will take low values or even be equal to zero. For such systems, the benefit of the solar heat will manifest itself in other performance indicators, in particular the seasonal performance factor of the system and, for systems with ground source regeneration, the ground source regeneration fraction.

In a similar manner one can define the solar electrical fraction as

$$
f_{\text {sol }, \text { el }}^{(\text {site } l \text { ocal }, 1)}=\frac{E_{*, \text { sys }}+E_{*, H E}-E_{\text {Grid,sys }}-E_{\text {Grid }, H E}}{E_{*, \text { sys }}+E_{*, H E}}=\underbrace{=\frac{E_{P V T, s y s}^{A C}+E_{P V T, H E}^{A C}}{E_{*, s y s}+E_{*, H E}}}_{\text {Only for systems without battery }}
$$

where one distinguishes between the electricity consumption of the heating system $E_{*, s y s}$ (including space heating and hot water) and of the household electricity $E_{*, H E} \cdot{ }^{4}$ More generally, $E_{*, H E}$ contains all the electricity consumption besides the one of the heating system, i.e. for example also the electricity consumption of an industrial process. $E_{P V T, s y s}^{A C}$ and $E_{P V T, H E}^{A C}$ denote the solar electricity used locally (self-consumption) for the heating system and household electricity, respectively. The superscript site is used if all electricity consumption of the site is included, i.e. both of the heating system and household electricity. Alternatively, one can replace site by either sys or $H E$ if only either the heating system or the household is considered. $f_{\text {sol,el }}^{\text {(sitelocal,1) }}$ is often referred to as the electricity self-sufficiency fraction or the degree of electrical self-sufficiency.

The label local means that solar electricity fed into the grid is ignored. Alternatively, if this is to be included, one can use the label net and define the solar electrical fraction as

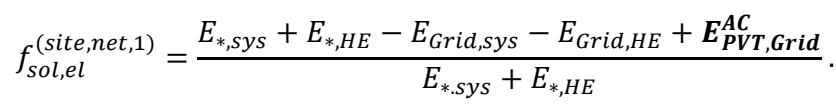

\footnotetext{
${ }^{4}$ If a battery is present, $E_{*, s y s}$ includes the consumption of all electricity consumers of the heating system, but it doesn't include losses of the battery, i.e. the battery is not considered to be a part of the heating and cooling system. However, $E_{*, s y s}$ includes electricity coming from the battery, i.e. $E_{*, s y s}=E_{P V T, s y s}+E_{B a t, s y s}+E_{\text {Grid,sys }}$.
} 
The above definitions of the solar electrical fraction with the label "1" are such that in systems with a battery, losses from charging and discharging the battery are accounted for. This means that a "bad" battery leads to a lower solar fraction. It is assumed that the battery is only charged by solar electricity and not by grid electricity. Alternatively, if the battery is also used for storing grid electricity, the above definition would not be "fair" in the sense that all the losses of the battery system are attributed to the solar electricity. In such cases it is advised to use the following definition ${ }^{5}$

$$
f_{\text {sol,el }}^{(\text {site, net }, 2)}=\frac{E_{P V T, s y s}^{A C}+E_{P V T, B a t}^{A C}+E_{P V T, H E}^{A C}+E_{P V T, G r i d}^{A C}}{E_{P V T, s y s}^{A C}+E_{P V T, B a t}^{A C}+E_{P V T, H E}^{A C}+E_{G r i d, s y s}+E_{G r i d, B a t}^{A C}+E_{\text {Grid,HE }}}=\frac{E_{P V T, \text { site }}^{A C}+E_{P V T, G r i d}^{A C}}{E_{P V T, \text { site }}^{A C}+E_{\text {Grid,site }}},
$$

or, with the label local, in which case $E_{P V T, \text { Grid }}^{A C}$ is removed from the numerator. Here and in the following formulas the index site signifies that all local components are included, i.e. heating system (sys), household electricity $(H E)$, and a possible battery (Bat), for instance $E_{P V T, s i t e}^{A C}=E_{P V T, s y s}^{A C}+E_{P V T, B a t}^{A C}+E_{P V T, H E}^{A C}$ denotes all the locally produced solar electricity that is used locally, either for the heating system, the household electricity, or for charging a battery. With this definition, the battery losses are not included. A "bad" battery leads to a higher solar electrical fraction if the battery is mainly charged with solar energy or to a lower solar fraction if the battery is mainly charged with grid electricity.

In systems without battery, definitions "1" and "2" are identical.

Finally, one can also define a local solar energy fraction, including both solar heat and electricity, as

$$
f_{\text {sol,en }}^{(\text {sitelocal })}=\frac{Q_{P V T, s y s}+E_{P V T, \text { site }}^{A C}}{Q_{*, \text { sys }}+E_{P V T, \text { site }}^{A C}+E_{\text {Grid,site }}} .
$$

\subsubsection{Electricity self-consumption fraction}

The electricity self-consumption fraction can be defined as

$$
f_{\text {self }, \text { el }}^{(\text {site } 1)}=\frac{E_{*, \text { sys }}+E_{*, H E}-E_{\text {Grid,sys }}-E_{\text {Grid }, H E}}{E_{P V T}^{A C}},
$$

in which case battery losses are included and fully attributed to (i.e. subtracted from) the solar electricity (Hence, this definition is not suitable for systems in which the battery is also charged by grid electricity), or by

$$
f_{\text {self }, e l}^{(\text {site } 2)}=\frac{E_{P V T, s y s}^{A C}+E_{P V T, B a t}^{A C}+E_{P V T, H E}^{A C}}{E_{P V T}^{A C}}=\frac{E_{P V T, \text { site }}^{A C}}{E_{P V T}^{A C}},
$$

in which case battery losses are not included (i.e. bad batteries lead to higher values) and which is also suitable for systems in which grid electricity is used for charging the battery. Like above, site can be replaced by $s y s$ or $H E$, depending on the analysis. For systems without battery, the two definitions are equivalent, $f_{\text {self }, e l}^{(1)}=f_{\text {self,el }}^{(2)}$.

\subsubsection{Local renewable energy fraction}

The local renewable energy fraction, i.e. the proportion of the energy flowing into the system that stems from local renewable energy sources, can be defined as

$$
f_{\text {ren }}^{(\text {site,local })}=\frac{Q_{*, \text { sys }}^{(\text {local }, \text { ren })}+E_{P V T, \text { site }}^{A C}}{Q_{*, \text { sys }}+E_{P V T, \text { site }}^{A C}+E_{\text {Grid,site }}} .
$$

Besides the heat provided by the PVT collectors, $Q_{*, \text { sys }}^{(\text {local,ren })}$ can include, for instance, geothermal heat. Like above, one can substitute the superscript site by sys or $H E$ if one only wants to consider the renewable energy fraction of the heating system or the household electricity. In the case of $H E$, the heat quantities will be set to zero. In a system that includes both a heating system and household electricity, the separate determination of $E_{P V T, S y s}^{A C}$ and $E_{P V T, H E}^{A C}$ will in general not be possible without some degree of arbitrariness. In a system with a battery, the splitting of $E_{P V T, B a t}^{A C}$ between the heating system and household electricity will also require assumptions.

\footnotetext{
${ }^{5} E_{P V T}^{A C}$ stands for the electricity that enters the system, i.e. before the battery. In a system with a DC-coupled battery, this value will not exist. For such cases it is suggested to use a value calculated as $E_{P V T}^{A C}=E_{P V T}^{D C} \cdot \eta_{D C / A C}$, with the inverter efficiency $\eta_{D C / A C}$.
} 
Instead of the local renewable energy fraction, one can define a net renewable fraction by replacing in the numerator $E_{P V T, s i t e}^{A C}$ by $E_{P V T}^{A C}$. This is the relation between the amount of renewable energy made available and the total amount of energy used. A positive value will indicate a surplus of available renewable energy. However, this quantity is going to be useful only in some particular cases.

$$
f_{\text {ren }}^{(\text {site,net })}=\frac{Q_{*, \text { sys }}^{(\text {local,ren })}+E_{P V T}^{A C}}{Q_{*, \text { sys }}+E_{P V T, \text { site }}^{A C}+E_{\text {Grid,site }}} .
$$

\subsubsection{Performance factor of a solar and heat pump system and fractional electricity savings}

The performance factor of a solar and heat pump system is defined as the ratio between the amount of useful heat heat $Q_{\text {use }}$ and/or cold $C_{\text {use }}$ provided and the electrical energy consumed by the system over a certain range of time. Usually it is calculated for a complete year and referred to as the seasonal performance factor. It can be written as

$$
S P F_{S H P+}^{(\text {total })}=\left[\frac{Q_{\text {use }}+C_{\text {use }}}{E_{*, \text { Sys }}}\right]_{S H P+},
$$

where "SHP + " is one of the options for the choice of the system boundaries, as defined in Task 44 (Hadorn 2015). According to this definition, the amounts of useful heat and cold are determined at the interfaces of the system with the heat/cold distribution systems and at the hot water tap. The consumed electrical energy includes the grid electricity consumption of all system components, including circulation pumps, fans etc. of the heat/cold distribution system. (SHP-boundaries are defined like $S H P+$, except that they do not include the electricity consumption of the heat/cold distribution system.). In order to clearly specify the system boundaries considered for the calculation of a performance factor, it is useful to draw the boundaries into a so-called "system square view", as defined in IEA Task 44 and extended in the present task to PVT systems (cf. subtask D report D6 "Visualization of Energy Flows in PVT Systems"). In systems that locally produce PV-electricity it is useful to also define a performance factor in which, instead of counting the total electrical energy consumed by the heating system (superscript total), one only considers the electricity taken from the grid

$$
S P F_{\text {SHP+ }}^{(\text {Grid })}=\left[\frac{Q_{\text {use }}+C_{\text {use }}}{E_{\text {Grid,sys }}}\right]_{\text {SHP+ }},
$$

Here, the self-consumed PVT electricity is not counted, since it is generated inside the system boundaries. ${ }^{6}$

The first two definitions do not account for electricity fed into the grid. An alternative definition, which also gives a value to the surplus electricity fed into the grid, is

$$
S P F_{S H P+}^{(n e t)}=\left[\frac{Q_{u s e}+C_{u s e}}{E_{\text {Grid,sys }}-E_{P V T, G r i d}^{A C}}\right]_{S H P+} .
$$

In cases where the generated amount of solar electricity is larger than the electricity consumed by the heating system, this quantity turns negative. In such a case, it can no longer be interpreted as a performance factor. Its inverse value, however, can always be interpreted as the amount of electricity taken, or, if negative, fed into the grid per unit of provided heat.

For the comparison of two heat pump systems (that provide the same, or similar amounts of useful energy), e.g. one with solar collectors (solar) and one without ( $r e f)$, a useful quantity are the so-called fractional electricity savings, defined as

$$
f_{\text {sav }, \text { el }}^{\text {SHP+,(total })}=1-\frac{\left(S P F_{S H P+}^{(\text {total })}\right)_{r e f}}{\left(S P F_{S H P+}^{(t o t a l)}\right)_{\text {solar }}},
$$

which again can be defined with different system boundaries and with the different superscripts.

\footnotetext{
6 This is consistent with the way solar heat is treated.
} 


\subsubsection{Final energy savings}

Heating systems with solar thermal components commonly include a back-up system, based on e.g. oil, gas or grid electricity. The reduction of the final energy consumption due to the presence of the solar energy system can be quantified by the final energy savings

$$
F E_{\text {sav }}^{\text {sys }}=\sum_{\begin{array}{c}
\text { i=final energy } \\
\text { carrier }
\end{array}} F E_{\text {sav }, i}^{\text {sys }},
$$

where $F E_{\text {sav }, i}^{\text {sys }}$ are savings of final energy put into the system in the form of the energy carrier $i$ (e.g. oil, gas, or grid electricity) compared to a reference system. In the case of combustibles, the upper heating value is considered. The reference system will typically be a "fictitious" system, similar to the solar energy system, but without solar energy. The final energy savings on a combustible are calculated with the subsequent formula. In cases where the total final energy consumption of the systems is not known, the savings on a combustible, e.g. gas, can be estimated with the help of the burner efficiency $\eta_{\text {gas }}$ (units of heat provided per final energy consumed in units of upper heating value).

$$
F E_{\text {sav }, \text { gas }}^{\text {sys }}=\left(Q_{F E, \text { gas }}\right)_{\text {ref }}-\left(Q_{F E, \text { gas }}\right)_{\text {solar }} \simeq \frac{Q_{P V T}^{\text {(direct })}}{\eta_{\text {gas }}},
$$

where $Q_{F E, i}$ is the amount of final energy (upper heating value) put into the system by means of the energy carrier $i$ (e.g. oil or gas).

The grid electricity savings are calculated with the following formula. In cases where the grid electricity consumption is not known, they can be estimated with the help of the seasonal performance factor $S P F_{b S t}^{(t o t a l)}$, where the subscript $b S t$ denotes the system boundaries "before storage" i.e. including all system components before the thermal storage tank (as in Ref. Hadorn 2015).

$$
F E_{\text {sav, grid electricity }}^{\text {sys }}=\left(E_{\text {Grid,sys }}\right)_{\text {ref }}-\left(E_{\text {Grid,sys }}\right)_{\text {solar }} \simeq \frac{Q_{P V T}^{(\text {direct })}}{\left(S P F_{b S t}^{(t o t a l)}\right)_{\text {ref }}}+E_{P V T, \text { sys }}^{A C} .
$$

If the total amounts of final energy consumption are known, a very useful quantity for comparing different systems are the fractional final energy savings for the different forms of final energy (FE), defined as

$$
f_{\text {sav }, F E}^{\text {sys }}=\frac{\sum_{i=\text { final energy carrier }} F E_{\text {sav }, i}}{\sum_{i=\text { combustible }}\left(Q_{F E, i}\right)_{\text {ref }}+\left(E_{\text {Grid,sys }}\right)_{\text {ref }}} .
$$

For a system with no consumption of combustibles, this is equal to the fractional electricity savings (Eq. 28) with the superscript (Grid). Depending on the context, it can also be useful to relate the final energy savings to the gross collector field area.

\subsubsection{Ground source regeneration fraction}

Especially for heat pump systems with large ground source borehole fields, the regeneration of the ground source can be advantageous or even necessary. A valuable indicator in this context is the ground source regeneration fraction, which in cases where the regeneration is solely done with PVT collectors, can be defined as

$$
f_{\text {reg,GS }}=\frac{Q_{P V T, G S}}{Q_{G S, H P}}
$$

where $Q_{P V T, G S}$ denotes the solar heat from the collector field injected to the ground source and $Q_{G S, H P}$ the heat extracted from the ground source by the heat pump. 


\subsection{Environmental KPI's}

\subsubsection{Non-renewable primary energy factor and savings}

The non-renewable primary energy consumption of the system over a certain period of time (typically a year) is given by

$$
\begin{aligned}
P E_{n r}^{\text {sys, (total) }}=\sum_{i=\text { combustible }} Q_{F E, i} \cdot C E D_{i}^{n r}+E_{\text {Grid,sys }} \cdot C E D_{\text {Grid el. }}^{n r} . \\
+\sum_{i=\text { infrastructure component }}^{C E D_{i}^{n r} / S L_{i},}
\end{aligned}
$$

where $Q_{F E, i}$ again is the amount of final energy (upper heating value) put into the system by means of the combustible energy carrier $i$ (e.g. oil, gas, ...) and $C E D_{i}^{n r}$ is the cumulated non-renewable energy demand per unit of final energy of an energy carrier, per unit of grid electricity $\left(C E D_{\text {Grid el. }}^{n r}\right)$, or of the considered infrastructure component. Concerning the method of the cumulative energy demand see Ref. (Frischknecht et al. 2007). $S L_{i}$ denotes the service life of the considered infrastructure component (typically in units of years). The third term in principle includes all system components (e.g. solar collectors, mounting system, heat pump, circulating pumps, piping, etc.). However, in practice, for reasons of simplicity, only the most relevant components, if at all, should be considered. ${ }^{7}$ Typical $C E D^{n r}$-values for combustibles and grid electricity are given in Table 1. Values for some infrastructure components can also be found in the reference document referred to in the table caption.

Table 1: Typical values for the non-renewable cumulated energy demand (CED ${ }^{n r}$ ) and the global warming potential (GWP) of combustibles and grid electricity (European electricity mix ENTSO-E). The values are taken from the Swiss guideline document "KBOB Ökobilanzdaten im Baubereich" (Koordinationskonferenz der Bau- und Liegenschaftsorgane der öffentlichen Bauherren KBOB 2016).

\begin{tabular}{|l|l|c|c|}
\hline & Reference quantity & CED $^{\text {nr }}$ & GWP \\
\hline & & kWh oil-equivalents & kg CO 2 -equivalents \\
\hline Oil & kWh (upper heating value) & 1.23 & 0.301 \\
\hline Natural gas & kWh (upper heating value) & 1.06 & 0.228 \\
\hline Wood logs & kWh (upper heating value) & 0.116 & 0.027 \\
\hline Wood pellets & kWh (upper heating value) & 0.157 & 0.027 \\
\hline Grid electricity (ENTSO-E) & kWh & 2.89 & 0.524 \\
\hline
\end{tabular}

Like in the case of the system performance factor, one can define a net $P E_{n r}^{s y s,(n e t)}$ in order to also account for (i.e. give a benefit to) the electricity fed into the grid as follows

$$
\begin{aligned}
P E_{n r}^{\text {sys,(net) }}=\sum_{i=\text { combustible }} Q_{F E, i} \cdot C E D_{i}^{n r}+E_{\text {Grid,sys }} \cdot C E D_{\text {Grid el. }}^{n r} \\
\quad+\sum_{\begin{array}{c}
i=\text { infrastructure } \\
\text { component }
\end{array}} \frac{C E D_{i}^{n r}}{S L_{i}}-\boldsymbol{E}_{P V T, \text { Grid }}^{A C} \cdot \boldsymbol{C E} \boldsymbol{D}_{\text {Grid el. production }}^{n r} .
\end{aligned}
$$

Here, the electricity fed into the grid is counted as a negative contribution to the primary energy consumption. This is based on the assumption that this electrical energy is used by a consumer outside the system boundaries and substitutes the production of standard grid electricity. CED Grid el. production is the primary energy factor of the production of grid electricity. It is assumed here that the fed-in electricity only substitutes grid electricity production but does not substitute the impact of the transmission network and similar contributions.

\footnotetext{
${ }^{7}$ From a methodological point of view the inclusion of locally installed infrastructure is necessary, since the $C E D^{n r}$ -values of the final energy inputs also consider the infrastructure of upstream processes, i.e. power plants, refineries, etc.
} 
The non-renewable primary energy consumed per unit of provided useful energy is called the non-renewable primary energy factor and is defined as ${ }^{8}$

$$
P E F_{n r}^{\text {sys, }(\text { total })}=\frac{P E_{n r}^{s y s,(\text { total })}}{Q_{s y s}+C_{s y s}+E_{P V T, H E}^{A C}},
$$

or with the superscript (net). Instead of considering the total system with heat and electricity generation, one can also compute the primary energy consumptions and factors of the useful heat/cold $\left(Q_{s y s}\right.$ and $\left.C_{s y s}\right)$ and self-produced of household electricity $\left(E_{P V T, H E}^{A C}\right)$ separately.

Two systems, e.g. one with solar collectors (solar) and one without (ref) that roughly provide the same amounts of useful energy, can be compared by means of the fractional non-renewable primary energy savings

$$
f_{\text {sav }, p e}^{\text {sys }(\text { total })}=1-\frac{\left(P E F_{n r}^{\text {sys, }(\text { total })}\right)_{\text {solar }}}{\left(P E F_{n r}^{\text {sys },(\text { total })}\right)_{\text {ref }}} .
$$

\subsubsection{Global warming potential and global warming potential savings}

In a similar manner as the primary energy consumption, one can define the global warming potential GWP in units of $\mathrm{CO}_{2}$-equivalents as ${ }^{9}$

$$
\begin{aligned}
G W P^{\text {sys, (total) }}=\sum_{i=\text { combustible }} Q_{F E, i} \cdot G W P_{i}+E_{\text {Grid }, \text { sys }} \cdot G W P_{\text {Grid el. }} & \\
& \quad+\sum_{i=\text { infrastructure component }} \frac{G W P_{i}}{S L_{i}}+\sum_{i=\text { local emission }} A_{i} \cdot G W P_{i},
\end{aligned}
$$

where $G W P_{i}$ stands for the global warming potential of the different contributions. Typical GWP values for combustibles and grid electricity are provided in Table 1. $A_{i}$ denotes an amount per period of time (typically a year) of a local emission (e.g. refrigerant of a heat pump).

Again, one can include the benefit of electricity fed into the grid by defining a net-GWP as

$$
\begin{aligned}
& G W P^{\text {sys,(net) }}=\sum_{i=\text { combustible }} Q_{F E, i} \cdot G W P_{i}+E_{\text {Grid }, \text { sys }} \cdot G W P_{\text {Grid el }} .
\end{aligned}
$$

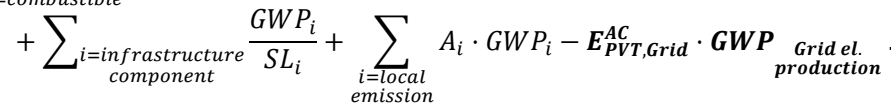

And also like in the case of the PE, one can define the global warming potential per unit of provided energy by the global warming potential factor

$$
G W F^{\text {sys,(total })}=\frac{G W P^{\text {sys,(total })}}{Q_{s y s}+C_{s y s}+E_{P V T, H E}^{A C}},
$$

or with the superscript (net). And one may also define the GWP or the GWPF of the heating, cooling and selfproduced household electricity systems separately.

For the comparison of different systems providing roughly the same amounts of useful energy, one can define the fractional global warming potential savings as

$$
f_{\text {sav }, \text { gwp }}^{\text {sys }(\text { total })}=1-\frac{\left(G W P F^{\text {sys, },(\text { total })}\right)_{\text {solar }}}{\left(G W P F^{\text {sys, },(\text { total })}\right)_{\text {ref }}},
$$

or with the superscript (net).

\footnotetext{
8 In the vocabulary of Task 44 this would correspond to the "primary energy effort figure". Here, it is suggested to use the term "primary energy factor", which seems to be more widespread. The definition differs from the one adapted in Task 44 by the inclusion of the infrastructure contribution ("grey energy") of the locally installed system. 9 The recent characterisation factors are given in Ref. (Stocker 2014).
} 


\subsection{Economic KPI's}

The total life cycle cost (TLCC) of a heat and electricity generating system including PVT collectors can be given by the sum of the present values of the investment (I) and the operation and maintenance costs (OM) minus the residual value (RV) of the system minus a possible remuneration for electricity fed into the grid (see e.g. (Sommerfeldt and Madani 2018) $)^{10}$.

$$
T L C C=I+O M-R V=I_{0}+\sum_{t=1}^{T=25}\left(O M_{t}-E_{P V T, \text { Grid }, t}^{A C} \cdot P_{\text {el. wholesale }, t}\right) \cdot(1+r)^{-t}-\frac{R V_{25}}{(1+r)^{25}} .
$$

$I_{0}$ is the initial investment, which, depending on the analysis, can be corrected by an obtained subsidy. $O M_{t}$ are investment and operation and maintenance costs in the year $t . r$ is the real discount rate, and $T$ the period of analysis in years. Here, we set $T=25$, reflecting a typical service life of a solar thermal installation. $R V_{25}$ stands for a possible residual value of the system, or parts of it, after 25 years. Typically, in the case of a residential system, the whole investment is done upfront. Smaller investments at later points in time (like the replacement of small components) can be included in $O M$. Also included in $O M$ are, among other contributions, the costs for electricity bought from the grid, i.e. $E_{\text {Grid,sys,t }} \cdot P_{\text {el. retail, },}$, where $P_{\text {el. retail,t }}$ is the electricity retail price in year $t$, and costs for fossil fuels. Depending on the context, and if not already included in the costs of fossil fuel, it can also include separate costs for $\mathrm{CO}_{2}$ emissions. $E_{P V T, G r i d, t}^{A C} \cdot P_{\text {el. wholesale, } t}$ is the remuneration for solar electricity fed into the grid in year $t$ with the corresponding electricity wholesale price $P_{\text {el. wholesale,t }}$.

In order to determine the costs of energy generated by the system, one can set the TLCC equal to the present value of the remuneration $P$ generated by the provided energy.

$$
\begin{aligned}
P \stackrel{\text { def }}{=} \sum_{t=1}^{T=25}\left(Q_{s y s, t}+\right. & \left.C_{s y s, t}+E_{P V T, H E, t}^{A C}\right) \cdot \operatorname{LCOEn} \cdot(1+r)^{-t} \\
& =I_{0}+\sum_{t=1}^{T=25}\left(O M_{t}-E_{P V T, G r i d, t}^{A C} \cdot P_{\text {el. wholesale }, t}\right) \cdot(1+r)^{-t}-\frac{R V_{25}}{(1+r)^{25}}
\end{aligned}
$$

LCOEn is the so-called levelised cost of energy generated by the system, which can be expressed as

$$
L C O E n=\frac{I_{0}+\sum_{t=1}^{T=25}\left(O M_{t}-E_{P V T, G r i d, t}^{A C} \cdot P_{\text {el. wholesale }, t}\right) \cdot(1+r)^{-t}-\frac{R V_{25}}{(1+r)^{25}}}{\sum_{t=1}^{T=25}\left(Q_{s y s, t}+C_{s y s, t}+E_{P V T, H E, t}^{A C}\right) \cdot(1+r)^{-t}} .
$$

Since heat, cold, and electricity are generally not considered to have the same value per unit of energy, it is useful to define the levelised costs of the different energy forms (LCOH, LCOC, and LCOE) separately.

$$
\begin{gathered}
L C O H=\frac{\left[I_{0}+\sum_{t=1}^{T=25} O M_{t} \cdot(1+r)^{-t}-\frac{R V_{25}}{(1+r)^{25}}\right]_{H S}}{\sum_{t=1}^{T=25} Q_{H S, t} \cdot(1+r)^{-t}}, \\
L C O C=\frac{\left[I_{0}+\sum_{t=1}^{T=25} O M_{t} \cdot(1+r)^{-t}-\frac{R V_{25}}{(1+r)^{25}}\right]_{C S}}{\sum_{t=1}^{T=25} C_{C S, t} \cdot(1+r)^{-t}}, \\
L C O E=\frac{\left[I_{0}+\sum_{t=1}^{T=25}\left(O M_{t}-E_{P V T, G r i d, t}^{A C} \cdot P_{\text {el. wholesale }, t}\right) \cdot(1+r)^{-t}-\frac{R V_{25}}{(1+r)^{25}}\right]_{E S}}{\sum_{t=1}^{T=25} E_{P V T, H E, t}^{A C} \cdot(1+r)^{-t}},
\end{gathered}
$$

where the terms in square brackets contain only the corresponding values for the heating system (HS), the cooling system (CS) or the electricity system (ES), respectively. This allocation (splitting) of the total life cycle costs to the different energy contributions is to some extent a matter of convention, e.g. one has to agree on how to split the costs of the PVT system between the heating system and the electricity system. 10 In the mentioned reference, the electricity fed into the grid is not included in the TLCC but in the remuneration.
This is merely a matter of choice. 
In the typical case of a combined solar energy plus conventional back-up system, one may also calculate the levelised costs of solar heat, cold, and electricity provided by the solar part of the system, by only counting the total life cycle costs associated to the solar energy part of the system.

Instead of calculating the cost of provided energy, one might also be interested in the cost of saved energy or avoided $\boldsymbol{C E D}$ or $\boldsymbol{G W P}$ compared to some reference system. To this aim, one can substitute in the above equations the energy quantities by these respective quantities.

One may further be interested in knowing the time, after which the financial savings achieved with the considered system compared to a reference system compensate the additional investment compared to the reference system. To this aim, one can make use the so-called discounted payback period (DPP), which is the time horizon for which the present values of the costs of the two compared systems are equal, i.e.

$$
\begin{gathered}
{\left[I_{0}+\sum_{t=1}^{T=D P P}\left(O M_{t}-\right.\right.} \\
\left.\left.E_{P V T, G r i d, t}^{A C} \cdot P_{\text {el. wholesale }, t}\right) \cdot(1+r)^{-t}-R V_{25} \cdot(1+r)^{-25}\right]_{\text {solar }} \\
=\left[I_{0}+\sum_{t=1}^{T=D P P} O M_{t} \cdot(1+r)^{-t}-R V_{25} \cdot(1+r)^{-25}\right]_{r e f}
\end{gathered}
$$

For a better understanding, it can be helpful to rearrange this equation in the following form

$$
\left(I_{0}\right)_{\text {solar }}-\left(I_{0}\right)_{\text {ref }}=\sum_{t=1}^{T=\text { DPP }}\left(F S_{O M, t}+R_{\text {Grid }, t}\right) \cdot(1+r)^{-t}+\Delta\left(R V_{25}\right) \cdot(1+r)^{-25}
$$

with the financial savings on operation and maintenance in year $t$

$$
F S_{O M, t}=\left(O M_{t}\right)_{r e f}-\left(O M_{t}\right)_{\text {sol }},
$$

the yearly remuneration for electricity fed to the grid

$$
R_{\text {Grid, } t}=E_{P V T, G r i d, t}^{A C} \cdot P_{\text {el. wholesale }, t},
$$

and the difference between the residual values of the two systems after 25 years

$$
\Delta\left(R V_{25}\right)=\left(R V_{25}\right)_{\text {solar }}-\left(R V_{25}\right)_{\text {ref }}
$$

The yearly financial savings $F S_{O M, t}$ contain all savings, or additional expenses, of the analysed system compared to the reference system. This also includes, among other contributions, the financial savings for reduced final energy consumption, or, for instance, the reduction of expenditures for carbon emission taxes. Depending on the analysis, it can be interesting to indicate such contributions separately, like e.g. the environmental penalty cost savings, as suggested in Ref. (Wang et al. 2019).

Instead of using the DPP, it is somewhat more common, to simply use the payback period PP, where future revenues are not discounted, which is the defined as (see e.g. (Herrando, Ramos, and Zabalza 2018))

$$
\left(I_{0}\right)_{\text {solar }}-\left(I_{0}\right)_{\text {ref }}=\sum_{t=1}^{T=P \boldsymbol{P}}\left(F S_{O M, t}+R_{\text {Grid }, t}\right)+\Delta\left(R V_{25}\right)
$$

An additional useful indicator for the comparison of different PVT systems can be the initial investment cost per square meter of collector area

$$
i_{0}^{P V T}=\frac{\left[I_{0}\right]_{P V T}}{A_{\text {gross }}^{P V T T}},
$$




\section{Application example 1 - Comparison of three buildings of the building complex Sotchà}

In the building complex Sotchà in Scuol (Switzerland) three identical apartment houses have been equipped with three different heating systems, each of which has a different type of solar installation (for more information on the systems and a detailed analysis of the systems consult the final project report Ref. (Vassella et al. 2020)). The buildings have a low heat demand, they qualify for the Swiss Minergy A label. A detailed monitoring system was installed that permits a comparison of the three energy systems. The example of Sotchà provides a good application case for the key performance indicators described in this document. We consider here the energy-related KPI's of the fourth year of operation of the systems, i.e. the measurement period from July 2018 to June 2019.

\subsection{System description}

Each of the three buildings of Sotchà has a power-adjustable brine/water heat pump ( $30 \mathrm{~kW}$ heating capacity) that is connected to an individual geothermal borehole field (five boreholes with a depth of 170 metres). The additional properties of the systems are as follows:

- House A:

PV system (132 m²; $22.1 \mathrm{kWp}$ electricity) with electrical battery (28 kWh). This building without regeneration of the ground source serves as the reference system.

- House B: In-roof PVT system developed by Caotec (130 m²; 21.8kWp electricity) with uncovered rear-insulated PVT collectors. The solar heat can be injected on the primary side of the heat pump via a brine buffer storage unit for the regeneration of the ground source and as source of the heat pump, or on the secondary side, for hot-water pre-heating and support of the space heating.

- House C: $\quad$ Solar thermal installation $\left(42 \mathrm{~m}^{2}\right)$ with "Alpsun Indach" roof-integrated flat-plate collectors by Caotec. The remainder of the surface of this roof was covered with PV modules (90 $\mathrm{m}^{2}, 15.1 \mathrm{kWp}$ electricity). The hydraulic integration of the solar heat is like in the case of House B.

The type of PV modules installed on buildings $A$ and $C$ is Capillary G/G $280 \mathrm{~W}$ by Sunage. All solar installations are oriented towards the south.

In all three systems the boreholes are also connected via a brine/air heat exchanger with the building ventilation system and are used to cool the building (in summer) and to pre-heat the inflow air (in winter). These functions, however, contribute very little to energy balance of the boreholes and are therefore neglected in the present discussion.

Further, since the household electricity consumption was not monitored in detail, only the heating system (hot water and space heating) is considered in this analysis. It is assumed that the heating system self-consumes all the solar electricity production that coincides with and doesn't exceed the electricity demand of the heating system. The remaining electricity production is assumed to be fed into the grid.

The complete square views, as introduced in Ref. (Frank et al. 2010) and extended for the inclusion of pvt collectors, electrical energy flows and storage ${ }^{11}$, of the three systems are shown in Figure 1 , and the square views with the mentioned simplifications, which are used for the present analysis, are shown in Figure 2.

11 See Subtask D report D6 "Visualization of Energy Flows in PVT Systems". 
Building A

Building B
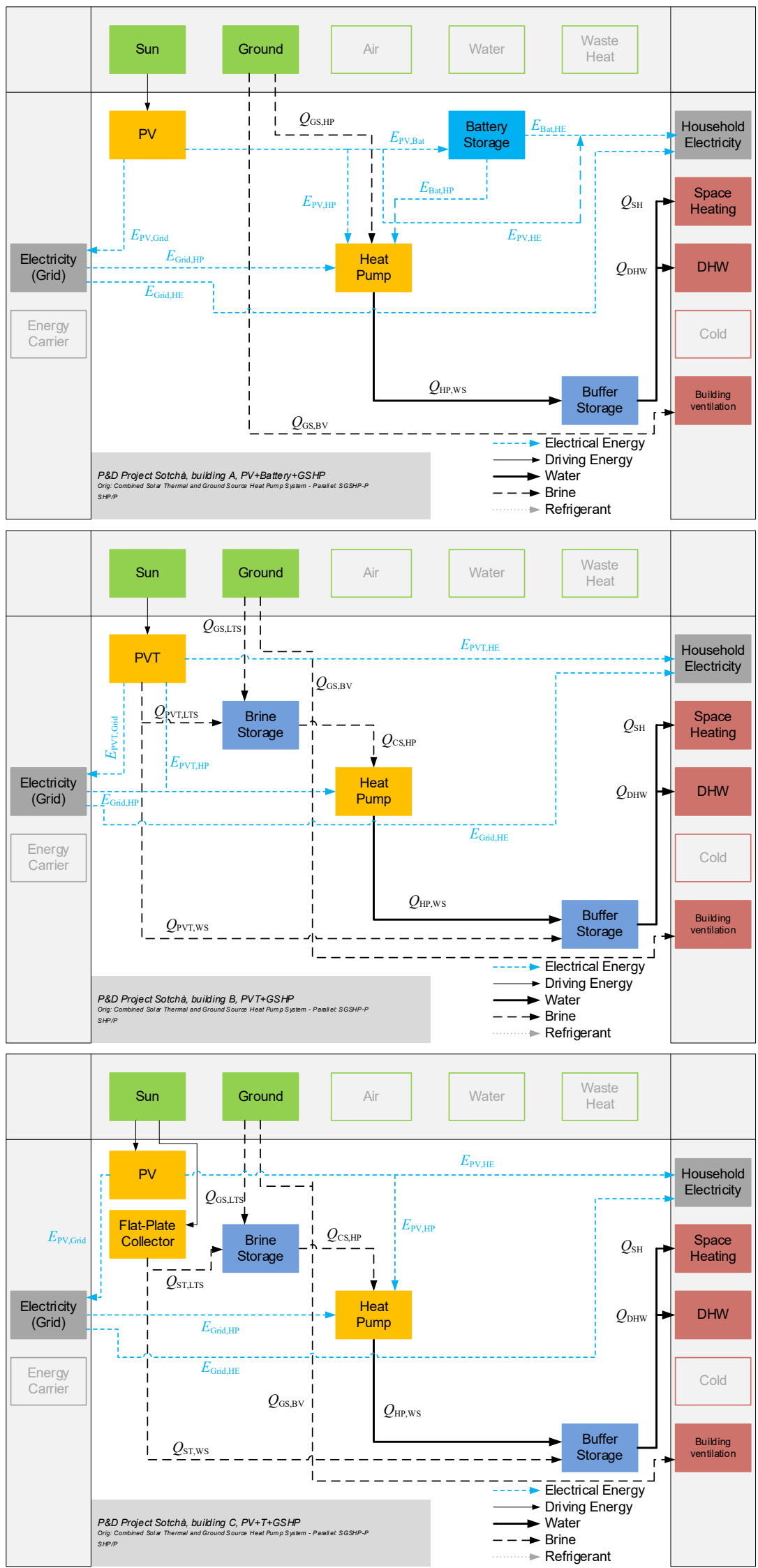

Figure 1: Full system square views of the three considered buildings of the Sotchà building complex. The buffer storage in reality consists of two storage tanks connected in series. (Later in the text the brine storage will also be called "low temperature storage" (LTS) and the buffer storage "warm storage" (WS).) 
Building A

Building B

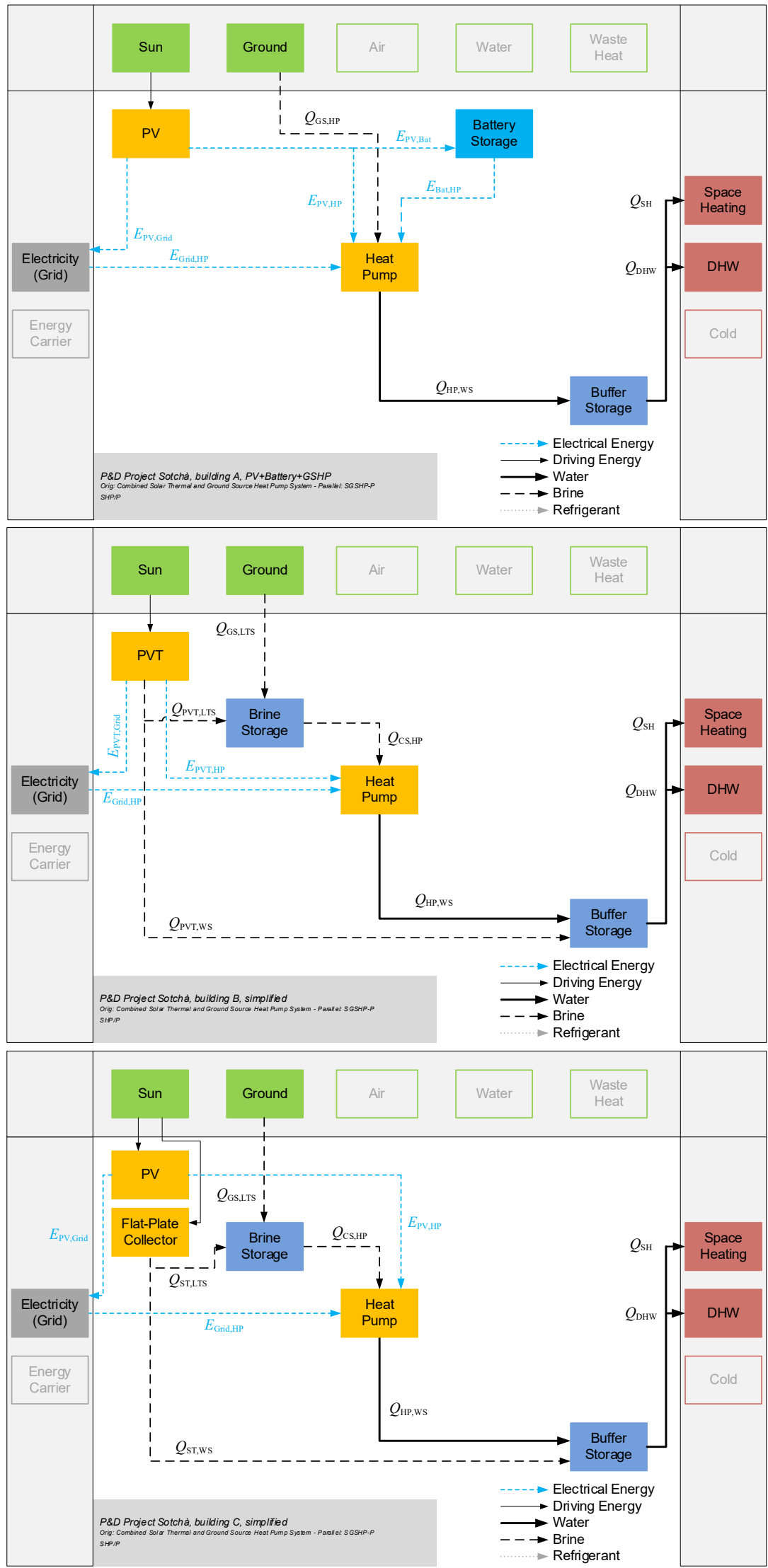

Figure 2: Simplified square views of the three Sotchà buildings. Household electricity and the connections of the ground sources with the building ventilation systems are not considered. (Later in the text, the brine storage will also be called "low temperature storage" (LTS) and the buffer storage "warm storage" (WS).) 


\subsection{Energy inputs and outputs}

As a basis for the subsequent discussion of the KPI's, Figure 3 shows the energy inputs and useful energy outputs of the three systems for the one-year period from July 2018 to June 2019. The system boundaries include the heat pump, the heat storage tanks, circulation pumps and controls. The PV and PVT panels, the flat plate-collectors, as well as the battery storage are considered to lie outside the system boundaries for this balance. The two patterned areas are additional benefits of the PV or PVT fields. These two energy flows ("solar electricity to grid" and "solar electricity self-consumed by households"), however, happen outside the chosen system boundaries and are therefore not to be considered in the corresponding energy balance. When judging the results for the KPI's, it is important to keep in mind that the heat consumptions of the three buildings are different. E.g. the space heating demand of building $B$ is lower compared to the other buildings. Further, the DHW demand of building $A$ is considerably larger than the corresponding demands of the other buildings. The thermal and electrical solar energy yields are shown in Figure 4.

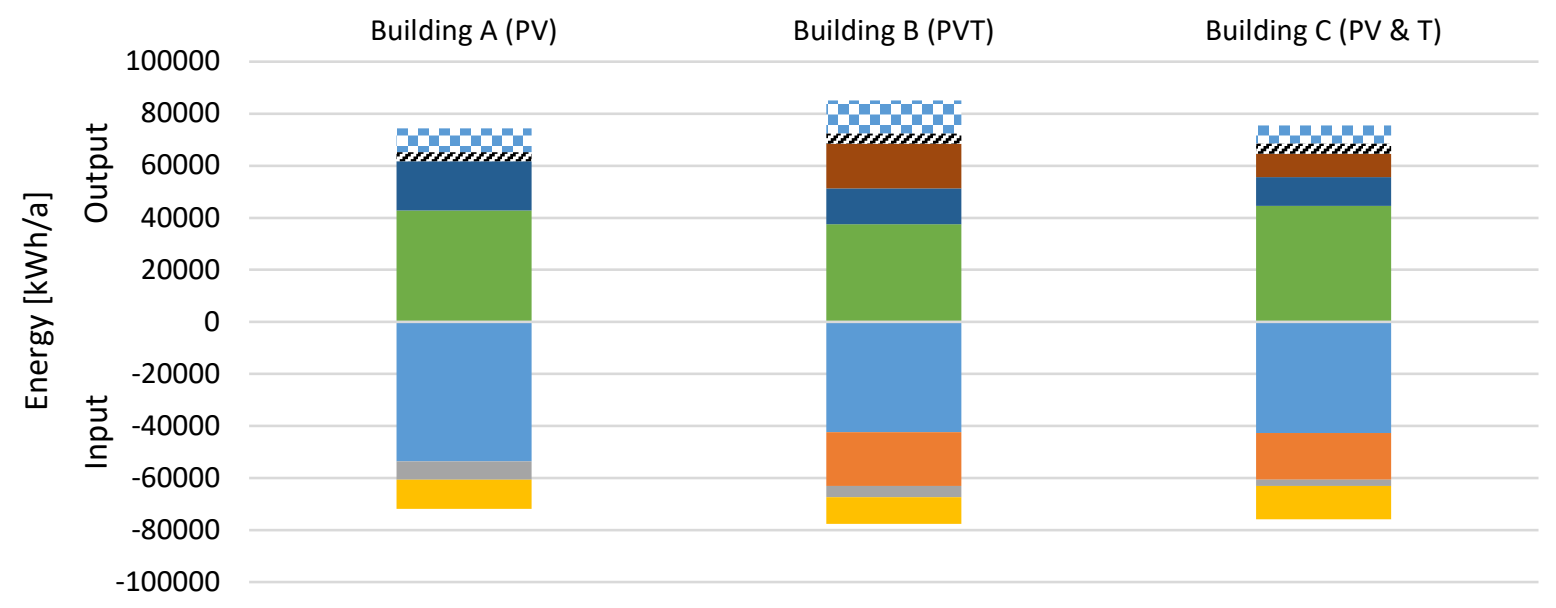

Ground heat

Solar electricity self-consumed by heating system

Space heating

- Solar heat to ground source (regeneration)

". Solar electricity to grid
Solar heat to system

Grid electricity to heating system

Hot water incl. Circulation

Z Solar electricity self-consumed by households

Figure 3: Energy inputs and useful energy outputs of the three energy systems at Sotchà.

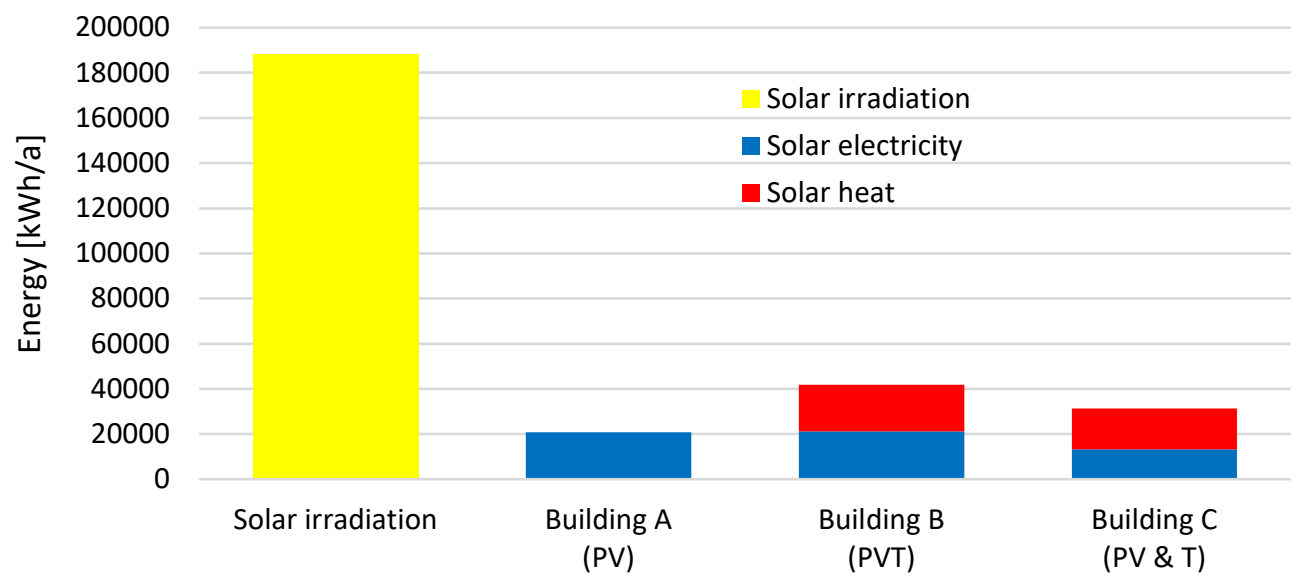

Figure 4: Electrical (DC) and thermal solar yields of the three systems at Sotchà. Also shown is the global solar irradiation on the collector plane. 


\subsection{Key performance indicators}

The formulas and values of the performance indicators defined previously in this document and relevant for this example case are listed below in Table 2. The measured quantities necessary for the computation of these KPI's are listed in Table 3.

The utilisation ratios are shown in Figure 5, related to the individual surface areas of the PVT, PV, and T fields (a) and related to the surface area of the complete solar field (b). Also indicated are characteristic operating temperatures of the two thermal components (PVT and T), namely the thermal output-weighted averages of the mean fluid temperatures $\vartheta_{\text {char,output }}^{\text {m }}$.

The component-related electrical utilisation ratios are in the same range for all three buildings. The slightly higher value of the PVT system (B) might partly be a consequence of the lower cell temperatures (and hence higher efficiencies) due to the heat extraction. However, several other factors can also have an influence on the electrical efficiency, for example the efficiency of the maximum-power-point (MPP-) trackers, shading effects, or differences in the effective output of the modules (deviations from the nominal output of $280 \mathrm{Wp}$ per module). The thermal utilisation ratio of the flat-plate collectors of building $C$ is clearly higher than the one of the PVT collectors of building $\mathrm{B}$. The thermal utilisation ratio is significantly higher for the flat plate collectors of building $\mathrm{C}$ compared to the uncovered PVT collectors of building B. The corresponding annual thermal yields related to the respective gross collector area are $429 \mathrm{kWh} /\left(\mathrm{m}^{2} \mathrm{a}\right)(\mathrm{T})$ and $159 \mathrm{kWh} /\left(\mathrm{m}^{2} \mathrm{a}\right)$ (PVT). Considering the characteristic operating temperature of almost $37^{\circ} \mathrm{C}$, the yield of the PVT system is within the expected range. ${ }^{12}$ Nevertheless, if one considers solar heat yields of similar systems (PVT for ground source regeneration), they can be significantly higher. This is due to the fact that their operating temperatures are usually lower, i.e. in the range of $20{ }^{\circ} \mathrm{C}$, resulting in area-specific solar heat yields around $300 \mathrm{kWh} /\left(\mathrm{m}^{2} \mathrm{a}\right)$, and corresponding to a thermal utilisation ratio of about $20 \%$.

The solar utilisation ratios related to the complete solar installation (Figure $5 \mathrm{~b}$ )) show a different picture. The PVT system (building B) achieves the highest value for all three indicators. The electrical utilisation ratio is higher than in building $A$ for the reasons already mentioned in the component comparison, and it is higher than in building $\mathrm{C}$, due to the larger electrically active surface. Furthermore, despite the lower efficiency at component level, building B generates more solar heat than building $C$, thanks to the larger thermally active surface, and at almost the same typical temperature. Consequently, the solar energy utilisation ratio of the roof (the sum of the electrical and thermal utilisation ratios) is clearly highest for building $B$ (PVT). In terms of this indicator, building $C$ is ahead of building $A$. However, since A produces more solar electricity, the value of which is higher than that of the solar heat from $C$, this indicator should only be used in combination with other indicators, such as the seasonal performance factor of the systems, to compare Systems A and C.

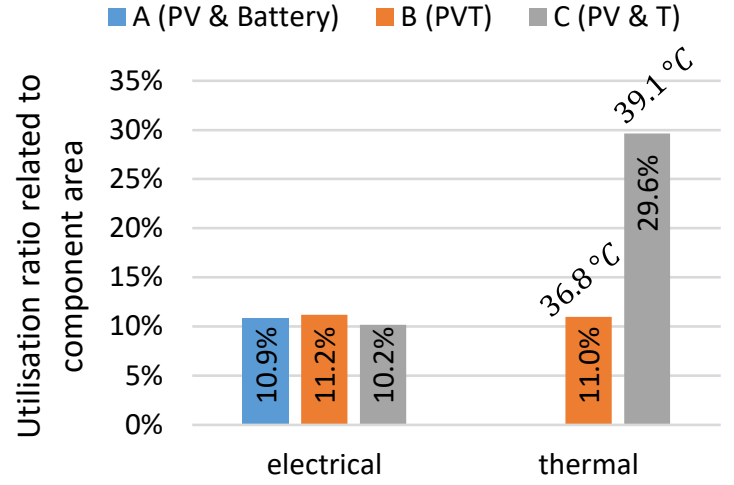

a)

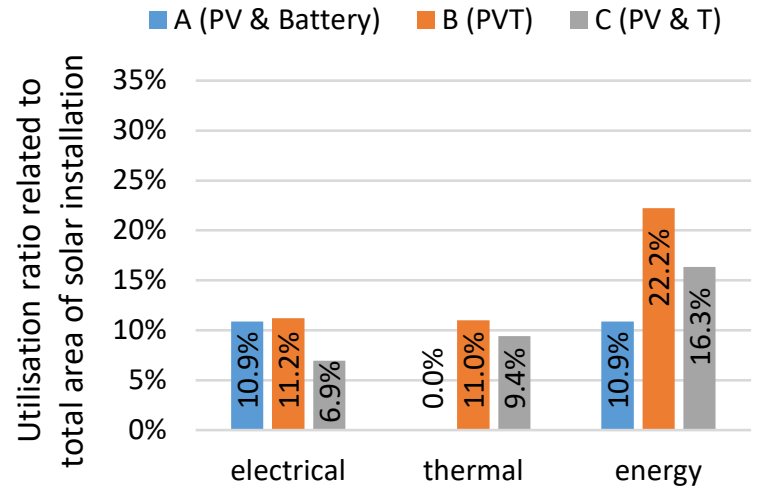

b)

Figure 5: (a) Solar utilisation ratios related to the surface areas of the individual solar component fields, i.e. PV, $P V T$, or $T\left(\omega_{P V / P V T, e l}^{D C, g r o s s}\right.$ and $\left.\omega_{P V T / T, t h}^{g r o s s}\right)$ and $(b)$ related to the total surface area of the solar installations of the respective building $\left(\omega_{\text {sol,th }}^{\text {gross }}, \omega_{\text {sol,el }}^{D C, \text { gross }}\right.$, and $\left.\omega_{\text {sol,en }}^{\text {DC,gross }}\right)$.

\footnotetext{
12 See e.g. Zenhäusern D., Bamberger E. and Baggenstos A., "PVT-WrapUp", issued by EnergieSchweiz (Swiss Federal Office of Energy), 2017.
} 
The performance of the three heat pumps can be compared by means of the seasonal performance factors of the heat pumps $\boldsymbol{S P} \boldsymbol{F}_{H \boldsymbol{P}}$ (Figure 6). The values of all three heat pumps are very similar, around 4.5. The differences lie in the range of the measurement uncertainty. Since the consumption profiles for hot water and space heating differ considerably between the three buildings, the $S P F_{H P}$ was also calculated separately for the hot water and the space heating operation modes. This results in values of about 3.5 for the hot water mode and 5.7 for the space heating mode. The difference between house $A$ and $B$ is only about $5 \%$ also with this approach. Besides the heat consumption profiles, the $S P F_{H P}$ is also influenced by various other factors. For example, in systems $\mathrm{B}$ and $\mathrm{C}$, where the heat storage tank is partially heated with solar heat, the sink temperatures of the heat pump will have to be somewhat higher on average, which has a negative influence on the $S P F_{H P}$. On the other hand, the heat pumps of $B$ and $C$ will have higher source temperatures than $A$, since solar heat is also injected on the primary side, which has a positive influence on the $S P F_{H P}$. It can be expected that the $S P F_{H P}$ of the heat pumps $\mathrm{B}$ and $\mathrm{C}$ will improve somewhat in the long term compared to that of $A$ thanks to the ground source regeneration.

At the system level, it is interesting to compare the seasonal performance factors of the systems $\boldsymbol{S P F}_{\boldsymbol{S H} \boldsymbol{P}}$ (Figure 6). ${ }^{13}$ The $S P F_{S H P+}^{(\text {total })}$ is lower than the $S P F_{H P}$ because various heat losses (especially storage losses) are subtracted from the delivered heat and because the electricity consumption of additional components, like circulation pumps and controls, is taken into account. Solar heat directly injected to the heat storage tank has a positive effect because it reduces the electricity consumption of the compressor. As a consequence, system $\mathrm{C}$, where most solar heat is injected on the secondary side, has the highest value, followed by system $\mathrm{B}$.

Compared to the $S P F_{S H P+}^{(t o t a l)}$, the $S P F_{S H P+}^{(g r i d)}$ is the higher, the more locally generated solar electricity is available for the heating system, i.e. the more the grid consumption is reduced. This effect is clearly highest in system $A$, thanks to the battery storage (analogous to the electricity self-consumption fraction), which is why the seasonal performance factor related to the grid electricity consumption is highest in this system. However, system B (PVT) also achieves a significantly higher value than system C (PV\&T).

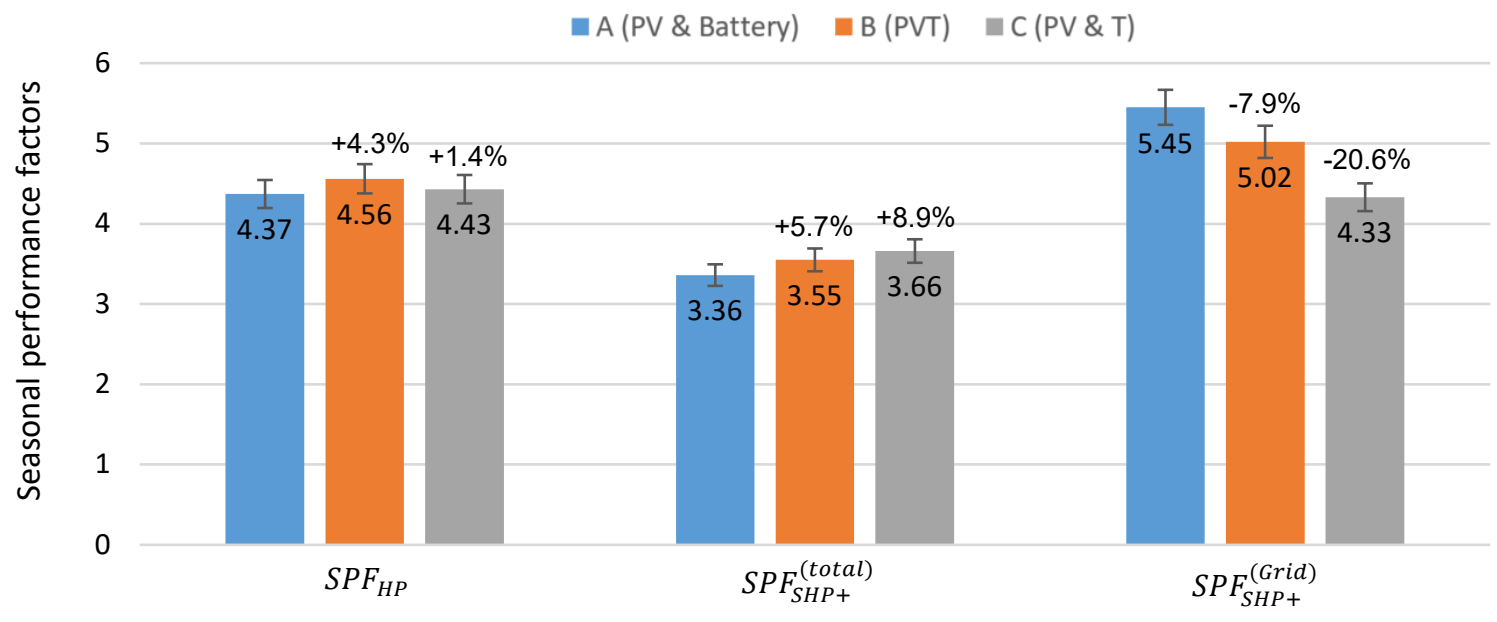

Figure 6: Seasonal performance factors of the three systems, at the level of the heat pump $\left(S P F_{H P}\right)$ and of the complete system including storage tanks and the solar energy systems, considering the total electricity consumption of the system $\left(S P F_{S H P+}^{(t o t a l)}\right)$, and considering only the consumed grid electricity $\left(S P F_{S H P+}^{(G r i d)}\right)$. The percentage values indicate the difference compared to building $A$.

In order to also account for the solar electricity fed to the grid, one can consider the $S P F_{S H P+}^{(n e t)}$, or its inverse value, which is easier to interpret (Figure 7). It can be seen that per unit of provided useful heat, and balanced over a full year, buildings $C$ takes 0.035 units of electricity from the grid, while building A (PV) feeds 0.022 and building $B$ (PVT) 0.125 units of electricity to the grid, making the latter two "net electricity producers". Judging by this KPI, building $B(P V T)$ has an advantage over the two other buildings.

\footnotetext{
13 Unlike in the prescription of Task 44, in this example we treat the heat needed for compensating hot water circulation losses as useful heat.
} 


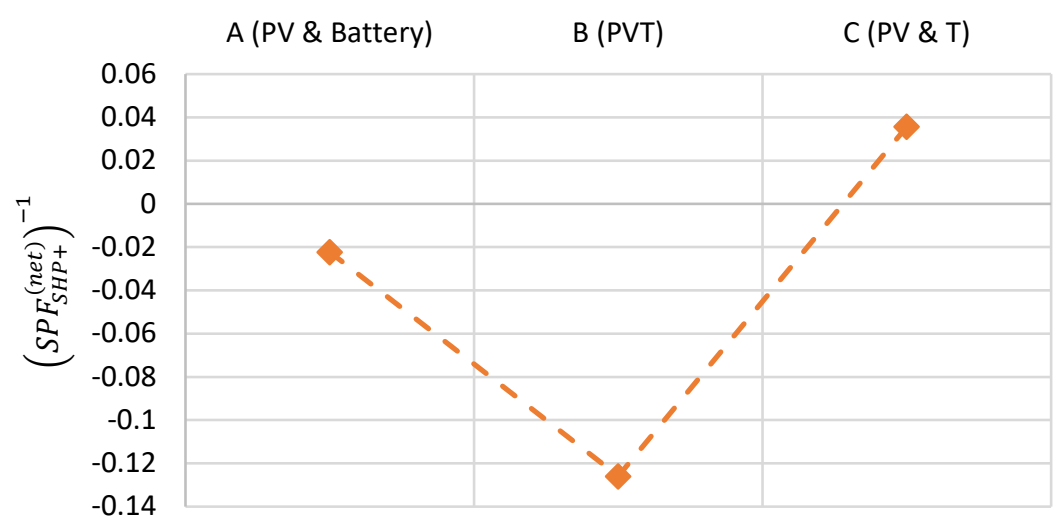

Figure 7: Comparison of the three systems in terms of $\left(S P F_{S H P+}^{(n e t)}\right)^{-1}$, which can be interpreted as the net number of units of electricity taken from the grid (balanced over a full year) per unit of useful heat provided.

A series of additional energy-related KPI's is shown in Figure 8 and discussed in the following paragraphs.

Building $\mathrm{C}$ (PV \& $\mathrm{T}$ ) has the highest solar thermal fraction $f_{\text {sol,th }}$, since the flat-plate collectors deliver about twice as much heat to secondary side compared to the uncovered PVT collectors.

The local solar electrical fraction or electricity self-sufficiency fraction $f_{\text {sol,el }}^{(\text {sys,local,1) }}$ has the highest value for building A with $38.5 \%$, even though the electricity consumption of system A is $20-25 \%$ higher than in the other systems. This is because building $A$ has a battery, which allows to significantly increase its electricity selfconsumption. House $\mathrm{C}$ has the clearly lowest value due to the small size of the photovoltaic system.

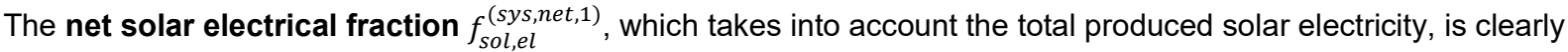
highest for the PVT system (building B), with $144.6 \%$. A value higher than $100 \%$ means that on a yearly basis, more solar electricity is consumed than electricity is consumed by the system. If system $A$ had the same electricity consumption as $\mathrm{B}$, it would reach a similar net solar electrical fraction. The presence of a battery has no influence on this indicator. Building C clearly has the lowest value, because of its smaller PV surface area, and doesn't reach a positive annual balance.

The local solar energy fraction $f_{\text {sol,en }}^{(\text {sys,local })}$ has the highest value for the PVT system (building B). Unlike in the solar thermal fraction, here, also the solar heat used on the primary side of the heat pump is considered. Building A has clearly the lowest value, because it does not produce solar heat.

The electricity self-consumption fraction $f_{\text {self,el }}^{(s y s, 1)}$ is clearly highest for building A because of the battery. For $\mathrm{B}$ and $\mathrm{C}$ this indicator takes similar values.

All three buildings have very similar local renewable energy fractions $f_{\text {ren }}^{(\text {sys,local })}$ of about $80 \%$, where geothermal heat is assumed to be renewable.

The net renewable energy fraction $f_{\text {ren }}^{(\text {sys,net })}$ shows that building B (PVT) makes available more renewable energy than it consumes energy in total. The value of building $A$ is around $100 \%$ while building $C$ shows a slightly lower value. A way of interpreting this $\mathrm{KPI}$ is to say that systems with values greater or equal to $100 \%$ have, with appropriate storage technology, the potential of being $100 \%$ renewable. 


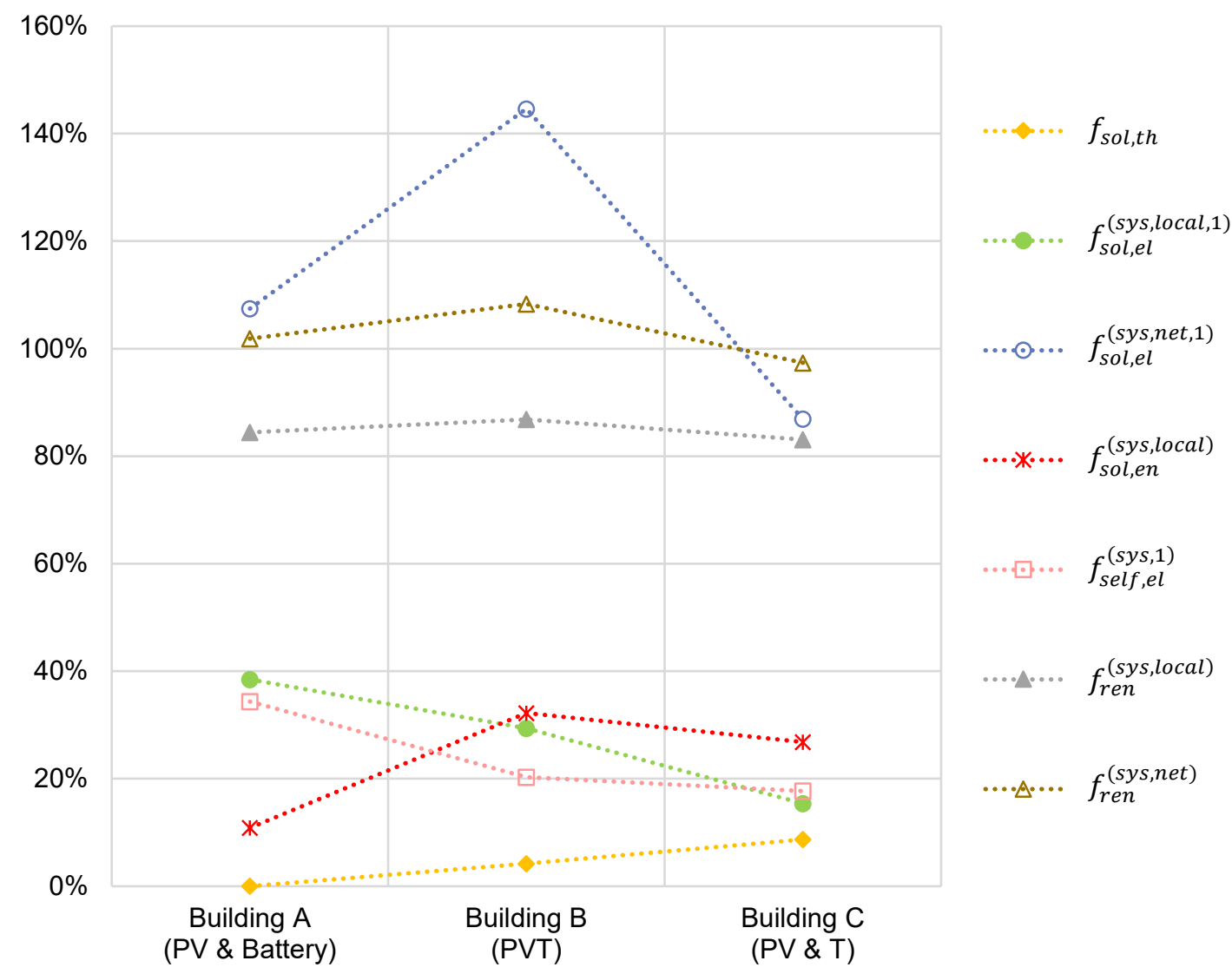

Figure 8: Comparison of solar fractions, electrical self-consumption fractions and renewable energy fractions of the three Sotchà buildings. 
Table 2: Expressions and values of most relevant energy-related KPI's for the three Sotchà systems.

\begin{tabular}{|c|c|c|c|c|}
\hline KPI & Units & Building A (PV) & Building B (PVT) & Building C (PV\&T) \\
\hline \multirow{3}{*}{$\omega_{P V T / T, t h}^{g r o s s}$} & \multirow{3}{*}{$\%$} & & $Q_{P V T}$ & $Q_{T}$ \\
\hline & & - & $\overline{A_{P V T}^{g r o s s} \cdot \int G_{c o l} d t}$ & $\overline{A_{T}^{g r o s s} \cdot \int G_{\text {col }} d t}$ \\
\hline & & - & 11.0 & 29.6 \\
\hline \multirow{3}{*}{$\omega_{P V T / P V, e l}^{D C, g r o s s}$} & \multirow{3}{*}{$\%$} & $E_{P V}^{D C}$ & $E_{P V T}^{D C}$ & $E_{P V}^{D C}$ \\
\hline & & $\overline{A_{P V}^{g r o s s} \cdot \int G_{c o l} d t}$ & $\overline{A_{P V T}^{g r o s S} \cdot \int G_{\text {col }} d t}$ & $\overline{A_{P V}^{g r o s s} \cdot \int G_{c o l} d t}$ \\
\hline & & 10.9 & 11.2 & 10.2 \\
\hline \multirow{3}{*}{$\omega_{\text {sol,th }}^{\text {gross }}$} & \multirow{3}{*}{$\%$} & & $Q_{P V T}$ & $Q_{T}$ \\
\hline & & - & $\overline{A_{P V T}^{g r o s s} \cdot \int G_{\text {col }} d t}$ & $\left(A_{P V}^{\text {gross }}+A_{T}^{\text {gross }}\right) \cdot \int G_{c o l} d t$ \\
\hline & & - & 11.0 & 9.4 \\
\hline \multirow{3}{*}{$\omega_{\text {sol,el }}^{D C, \text { gross }}$} & \multirow{3}{*}{$\%$} & $E_{P V}^{D C}$ & $E_{P V T}^{D C}$ & $E_{P V}^{D C}$ \\
\hline & & $\overline{A_{P V}^{\text {gross }} \cdot \int G_{\text {col }} d t}$ & $\overline{A_{P V T}^{g r o s s} \cdot \int G_{\text {col }} d t}$ & $\left(A_{P V}^{\text {gross }}+A_{T}^{\text {gross }}\right) \cdot \int G_{c o l} d t$ \\
\hline & & 10.9 & 11.2 & 6.9 \\
\hline \multirow{3}{*}{$\omega_{\text {sol,en }}^{D C, \text { gross }}$} & \multirow{3}{*}{$\%$} & $E_{P V}^{D C}$ & $Q_{P V T}+E_{P V T}^{D C}$ & $Q_{T}+E_{P V}^{D C}$ \\
\hline & & $\overline{A_{P V}^{\text {gross }} \cdot \int G_{c o l} d t}$ & $\overline{A_{P V T}^{g r o s s} \cdot \int G_{\text {col }} d t}$ & $\left(A_{P V}^{\text {gross }}+A_{T}^{\text {gross }}\right) \cdot \int G_{c o l} d t$ \\
\hline & & 10.9 & 22.2 & 16.3 \\
\hline \multirow[t]{2}{*}{$Y_{P V T / P V}^{A C}$} & \multirow[t]{2}{*}{$\mathrm{kWh} / \mathrm{kWp}$} & $\frac{E_{P V}^{A C}}{E_{P V}^{D C, S T C}}$ & $\frac{E_{P V T}^{A C}}{E_{P V T}^{D C, S T C}}$ & $\frac{E_{P V}^{A C}}{E_{P V}^{D C, S T C}}$ \\
\hline & & 930 & 958 & 873 \\
\hline \multirow{3}{*}{$P R_{P V T / P V}$} & \multirow{3}{*}{$\%$} & $Y_{P V}^{A C} \cdot 1 \mathrm{~kW} / \mathrm{m}^{2}$ & $Y_{P V T}^{A C} \cdot 1 \mathrm{~kW} / \mathrm{m}^{2}$ & $Y_{P V}^{A C} \cdot 1 \mathrm{~kW} / \mathrm{m}^{2}$ \\
\hline & & $\int G_{c o l} d t$ & $\int G_{c o l} d t$ & $\int G_{c o l} d t$ \\
\hline & & 65.1 & 67.1 & 61.1 \\
\hline \multirow[t]{2}{*}{$f_{\text {sol,th }}$} & \multirow[t]{2}{*}{$\%$} & - & $\frac{Q_{P V T, W S}}{Q_{P V T, W S}+Q_{H P, *}}$ & $\frac{Q_{T, W S}}{Q_{T, W S}+Q_{H P, *}}$ \\
\hline & & - & 4.2 & 8.7 \\
\hline \multirow{2}{*}{$f_{\text {sol,el }}^{(\text {sys,local }, 1)}$} & \multirow[t]{2}{*}{$\%$} & $\frac{E_{*, \text { sys }}-E_{\text {grid,sys }}}{E_{*, \text { sys }}}$ & $\frac{E_{*, \text { sys }}-E_{\text {grid,sys }}}{E_{*, \text { sys }}}$ & $\frac{E_{*, \text { sys }}-E_{\text {grid,sys }}}{E_{*, \text { sys }}}$ \\
\hline & & 38.5 & 29.4 & 15.4 \\
\hline \multirow[t]{2}{*}{$f_{\text {sol,el }}^{(\text {sys net }, 1)}$} & \multirow[t]{2}{*}{$\%$} & $\frac{E_{*, \text { sys }}-E_{\text {grid,sys }}+E_{P V, \text { grid }}^{A C}}{E_{*, \text { sys }}}$ & $\frac{E_{*, \text { sys }}-E_{\text {grid,sys }}+E_{P V T, \text { grid }}^{A C}}{E_{*, \text { sys }}}$ & $\frac{E_{*, \text { sys }}-E_{\text {grid,sys }}+E_{P V, \text { grid }}^{A C}}{E_{*, \text { sys }}}$ \\
\hline & & 107.5 & 144.6 & 86.9 \\
\hline \multirow{3}{*}{$f_{\text {sol,en }}^{(\text {sys,local })}$} & \multirow{3}{*}{$\%$} & $\left(E_{P V, *}^{A C}-E_{P V, \text { grid }}^{A C}\right)$ & $Q_{P V T, s y s}+E_{P V T, s y s}^{A C}$ & $Q_{T, s y s}+E_{P V, s y s}^{A C}$ \\
\hline & & $\left(E_{P V}^{A C}-E_{P V, \text { grid }}^{A C}\right)+E_{\text {grid,sys }}$ & $Q_{P V T, \text { sys }}+E_{*, \text { sys }}$ & $Q_{T, s y s}+E_{*, \text { sys }}$ \\
\hline & & 10.9 & 32.2 & 26.8 \\
\hline \multirow[t]{2}{*}{$f_{\text {self }, e l}^{(s y s, 1)}$} & \multirow[t]{2}{*}{$\%$} & $\frac{E_{P V, \text { sys }}^{A C}+E_{\text {bat }, \text { sys }}^{A C}}{E_{P V}^{A C}}$ & $\frac{E_{P V T, s y s}^{A C}}{E_{P V T}^{A C}}$ & $\frac{E_{P V, s y s}^{A C}}{E_{P V}^{A C}}$ \\
\hline & & 34.4 & 20.3 & 17.7 \\
\hline \multirow[t]{2}{*}{$f_{\text {self }, e l}^{(s y s, 2)}$} & \multirow[t]{2}{*}{$\%$} & $\frac{E_{P V, s y s}^{A C}+E_{P V, b a t}^{A C}}{E_{P V}^{A C}}$ & $\frac{E_{P V T, s y s}^{A C}}{E_{P V T}^{A C}}$ & $\frac{E_{P V, s y s}^{A C}}{E_{P V}^{A C}}$ \\
\hline & & 38.4 & 20.3 & 17.7 \\
\hline \multirow[t]{2}{*}{$f_{\text {ren }}^{(\text {sys,local })}$} & \multirow[t]{2}{*}{$\%$} & $\frac{Q_{*, \text { sys }}+\left(E_{P V}^{A C}-E_{P V, \text { grid }}^{A C}\right)}{Q_{*, \text { sys }}+\left(E_{P V}^{A C}-E_{P V, \text { grid }}^{A C}\right)+E_{\text {grid,sys }}}$ & $\frac{Q_{*, \text { sys }}+E_{P V T, s y s}^{A C}}{Q_{*, \text { sys }}+E_{*, s y s}}$ & $\frac{Q_{*, \text { sys }}+E_{P V, s y s}^{A C}}{Q_{*, s y s}+E_{*, s y s}}$ \\
\hline & & 84.5 & 86.8 & 83.1 \\
\hline$f_{\text {ren }}^{(s y s, n e t)}$ & $\%$ & $\frac{Q_{*, s y s}+E_{P V}^{A C}}{Q_{*, \text { sys }}+\left(E_{P V}^{A C}-E_{P V, g r i d}^{A C}\right)+E_{\text {grid,sys }}}$ & $\frac{Q_{*, \text { sys }}+E_{P V T}^{A C}}{Q_{*, \text { sys }}+E_{*, s y s}}$ & $\frac{Q_{*, s y s}+E_{P V}^{A C}}{Q_{*, s y s}+E_{*, s y s}}$ \\
\hline & & 101.9 & 108.3 & 97.4 \\
\hline
\end{tabular}




\begin{tabular}{|c|c|c|c|c|}
\hline \multirow{2}{*}{$S P F_{H P}$} & \multirow[t]{2}{*}{-} & $\frac{Q_{H P, *}}{E_{*, H P}}$ & $\frac{Q_{H P, *}}{E_{*, H P}}$ & $\frac{Q_{H P, *}}{E_{*, H P}}$ \\
\hline & & 4.37 & 4.56 & 4.43 \\
\hline \multirow{2}{*}{$S P F_{S H P+}^{(\text {total })}$} & \multirow[t]{2}{*}{-} & $\frac{Q_{S H}+Q_{D H W}+Q_{D H W \text { circ. }}}{E_{*, \text { sys }}}$ & $\frac{Q_{S H}+Q_{D H W}+Q_{D H W} \text { circ. }}{E_{*, s y S}}$ & $\frac{Q_{S H}+Q_{D H W}+Q_{D H W} \text { circ. }}{E_{*, \text { sys }}}$ \\
\hline & & 3.36 & 3.55 & 3.66 \\
\hline \multirow{2}{*}{$S P F_{S H P+}^{(g r i d)}$} & \multirow[t]{2}{*}{-} & $\frac{Q_{S H}+Q_{D H W}+Q_{D H W} \text { circ. }}{E_{\text {grid, sys }}}$ & $\frac{Q_{S H}+Q_{D H W}+Q_{D H W} \text { circ. }}{E_{\text {grid,sys }}}$ & $\frac{Q_{S H}+Q_{D H W}+Q_{D H W} \text { circ. }}{E_{\text {grid, sys }}}$ \\
\hline & & 5.45 & 5.02 & 4.33 \\
\hline \multirow{2}{*}{$S P F_{S H P+}^{(n e t)}$} & \multirow[t]{2}{*}{-} & $\frac{Q_{S H}+Q_{D H W}+Q_{D H W} \text { circ. }}{E_{\text {grid,sys }}-E_{P V, \text { grid }}^{A C}}$ & $\frac{Q_{S H}+Q_{D H W}+Q_{D H W} \text { circ. }}{E_{\text {grid,sys }}-E_{P V T, \text { grid }}^{A C}}$ & $\frac{Q_{S H}+Q_{D H W}+Q_{D H W} \text { circ. }}{E_{\text {grid,sys }}-E_{P V \text { grid }}^{A C}}$ \\
\hline & & -45.0 & -7.9 & 28.0 \\
\hline $1 / S P F_{S H P+}^{(n e t)}$ & - & -0.022 & -0.126 & 0.036 \\
\hline \multirow[t]{2}{*}{$f_{\text {sav }, e l}^{H P}$} & \multirow[t]{2}{*}{$\%$} & reference & $1-\frac{\left(S P F_{H P}\right)_{r e f}}{S P F_{H P}}$ & $1-\frac{\left(S P F_{H P}\right)_{r e f}}{S P F_{H P}}$ \\
\hline & & 0 & 4.2 & 1.4 \\
\hline \multirow[t]{2}{*}{$f_{\text {sav }, e l}^{S H P+,(t o t a l)}$} & \multirow[t]{2}{*}{$\%$} & reference & $1-\frac{\left(S P F_{S H P+}^{(\text {total })}\right)_{r e f}}{S P F_{S H P+}^{(\text {total })}}$ & $1-\frac{\left(S P F_{S H P+}^{(\text {total })}\right)_{r e f}}{S P F_{S H P+}^{(\text {total }}}$ \\
\hline & & 0 & 5.4 & 8.2 \\
\hline \multirow[t]{2}{*}{$f_{\text {sav }, e l}^{S H P+,(\text { grid })}$} & \multirow[t]{2}{*}{$\%$} & reference & $1-\frac{\left(S P F_{S H P+}^{(g r i d)}\right)_{r e f}}{S P F_{S H P+}^{(g r i d)}}$ & $1-\frac{\left(S P F_{S H P+}^{(g r i d)}\right)_{r e f}}{S P F_{S H P+}^{(g r i d)}}$ \\
\hline & & 0 & -8.6 & -25.9 \\
\hline \multirow[t]{2}{*}{$f_{\text {reg,GS }}$} & \multirow[t]{2}{*}{$\%$} & $\frac{Q_{*, G S}}{Q_{G S, H P}}$ & $\frac{Q_{L T S, G S}}{Q_{G S, L T S}}$ & $\frac{Q_{L T S, G S}}{Q_{G S, L T S}}$ \\
\hline & & 0 & 39.4 & 19.9 \\
\hline
\end{tabular}


Table 3: Measured yearly quantities of the three Sotchà buildings for the period from July 2018 to June 2019.

\begin{tabular}{|c|c|c|c|c|c|}
\hline Quantity & Units & $\begin{array}{c}\text { Building A } \\
\text { (PV) }\end{array}$ & $\begin{array}{c}\text { Building B } \\
\text { (PVT) }\end{array}$ & $\begin{array}{c}\text { Building C } \\
\text { (PV\&T) }\end{array}$ & \\
\hline $\int G_{c o l} d t$ & $\mathrm{kWh} /\left(\mathrm{a}^{*} \mathrm{~m}^{2}\right)$ & $1 ’ 428$ & $1 ’ 428$ & $1 ' 428$ & $\begin{array}{l}\text { Solar irradiation on } \\
\text { collector plane }\end{array}$ \\
\hline$Q_{P V T / T}$ & $\mathrm{kWh} / \mathrm{a}$ & - & $20 ’ 754$ & $18^{\prime} 005$ & Heat from PVT/T \\
\hline \multirow[t]{2}{*}{$q_{P V T / T}^{\text {gross }}$} & \multirow[t]{2}{*}{$\mathrm{kWh} /\left(\mathrm{a}^{*} \mathrm{~m}^{2}\right)$} & - & $\frac{Q_{P V T}}{A_{P V T}^{g r o S S}}$ & $\frac{Q_{T}}{A_{T}^{\text {gross }}}$ & \multirow{2}{*}{$\begin{array}{l}\text { Heat from PVT/T } \\
\text { related to gross } \\
\text { collector field area }\end{array}$} \\
\hline & & - & 159 & 429 & \\
\hline$Q_{P V T / T, W S}$ & $\mathrm{kWh} / \mathrm{a}$ & - & $2^{\prime} 446$ & $5^{\prime} 609$ & $\begin{array}{l}\text { Heat from PVT/T to } \\
\text { warm storage }\end{array}$ \\
\hline$Q_{P V T / T, L T S}$ & $\mathrm{kWh} / \mathrm{a}$ & - & $18^{\prime} 308$ & $12 ' 396$ & $\begin{array}{l}\text { Heat from PVT/T to } \\
\text { low temperature } \\
\text { storage }\end{array}$ \\
\hline$Q_{L T S, H P}$ & $\mathrm{kWh} / \mathrm{a}$ & - & $43^{\prime} 436$ & $45^{\prime} 624$ & $\begin{array}{l}\text { Heat from low } \\
\text { temperature storage } \\
\text { to heat pump }\end{array}$ \\
\hline$Q_{G S, H P}$ & $\mathrm{kWh} / \mathrm{a}$ & $53^{\prime} 552$ & - & - & $\begin{array}{l}\text { Heat from ground } \\
\text { source to heat pump }\end{array}$ \\
\hline$Q_{G S, L T S}$ & $\mathrm{kWh} / \mathrm{a}$ & - & $42 ' 377$ & $42 ' 738$ & $\begin{array}{l}\text { Heat from ground } \\
\text { source to low } \\
\text { temperature storage }\end{array}$ \\
\hline$Q_{L T S, G S}$ & $\mathrm{kWh} / \mathrm{a}$ & - & $17 ' 097$ & 9'073 & $\begin{array}{l}\text { Heat from low } \\
\text { temperature storage } \\
\text { to ground source }\end{array}$ \\
\hline$Q_{*, s y s}$ & $\mathrm{kWh} / \mathrm{a}$ & $53^{\prime} 552$ & $63^{\prime} 131$ & $60^{\prime} 743$ & Heat to system \\
\hline$Q_{H P, *}$ & $\mathrm{kWh} / \mathrm{a}$ & $69^{\prime} 240$ & $55^{\prime} 637$ & $58 ' 925$ & $\begin{array}{l}\text { Heat from heat } \\
\text { pump to other } \\
\text { components (warm } \\
\text { storage) }\end{array}$ \\
\hline$Q_{S H}$ & $\mathrm{kWh} / \mathrm{a}$ & $42 ' 743$ & $37^{\prime} 491$ & $44 ' 577$ & $\begin{array}{l}\text { Space heating } \\
\text { consumption }\end{array}$ \\
\hline$Q_{D H W}$ & $\mathrm{kWh} / \mathrm{a}$ & $14^{\prime} 724$ & 9'599 & $6 ’ 723$ & $\begin{array}{l}\text { Domestic hot water } \\
\text { consumption }\end{array}$ \\
\hline$Q_{D H W \text { circ }}$ & $\mathrm{kWh} / \mathrm{a}$ & 4'209 & $4^{\prime} 244$ & $4^{\prime} 278$ & $\begin{array}{l}\text { Heat consumption of } \\
\text { DHW circulation }\end{array}$ \\
\hline$E_{P V T / P V}^{D C}$ & $\mathrm{kWh} / \mathrm{a}$ & 20781 & $21 ' 151$ & $13^{\prime} 270$ & $\begin{array}{l}\text { Produced solar } \\
\text { electricity DC }\end{array}$ \\
\hline \multirow{2}{*}{$e_{P V T / P V}^{D C, \text { gross }}$} & \multirow{2}{*}{$\mathrm{kWh} /\left(\mathrm{a}^{*} \mathrm{~m}^{2}\right)$} & $\frac{E_{P V}^{D C}}{A_{P V}^{g r o s s}}$ & $\frac{E_{P V T}^{D C}}{A_{P V T}^{g r o s S}}$ & $\frac{E_{P V}^{D C}}{A_{P V}^{g r o s S}}$ & \multirow{2}{*}{$\begin{array}{l}\text { Produced solar } \\
\text { electricity DC related } \\
\text { to collector/module } \\
\text { field surface area }\end{array}$} \\
\hline & & 157 & 162 & 147 & \\
\hline$E_{P V T / P V}^{A C}$ & $\mathrm{kWh} / \mathrm{a}$ & $20 ’ 573$ & 20 '930 & $13 ’ 195$ & $\begin{array}{l}\text { Produced solar } \\
\text { electricity AC (for A } \\
\text { calculated from DC } \\
\text { yield with inverter } \\
\text { efficiency of 0.99) }\end{array}$ \\
\hline \multirow{2}{*}{$e_{P V T / P V}^{A C, \text { gross }}$} & \multirow{2}{*}{$\mathrm{kWh} /\left(\mathrm{a}^{*} \mathrm{~m}^{2}\right)$} & $\frac{E_{P V}^{A C}}{A_{P V}^{g r o s S}}$ & $\frac{E_{P V T}^{A C}}{A_{P V T}^{g r o s S}}$ & $\frac{E_{P V}^{A C}}{A_{P V}^{g r o s s}}$ & \multirow{2}{*}{$\begin{array}{l}\text { Produced solar } \\
\text { electricity AC related } \\
\text { to collector/module } \\
\text { field gross area }\end{array}$} \\
\hline & & 156 & 161 & 146 & \\
\hline
\end{tabular}




\begin{tabular}{|c|c|c|c|c|l|}
\hline$E_{P V T / P V, s y s}^{A C}$ & $\mathrm{kWh} / \mathrm{a}$ & $4^{\prime} 323$ & $4 ' 250$ & $2{ }^{\prime} 336$ & $\begin{array}{l}\text { Solar electricity to } \\
\text { heating system }\end{array}$ \\
\hline$E_{P V T / P V, \text { bat }}^{A C}$ & $\mathrm{kWh/a}$ & $7^{\prime} 894$ & - & $\begin{array}{l}\text { Solar electricity to } \\
\text { battery }\end{array}$ \\
\hline$E_{P V T / P V, \text { grid }}^{A C}$ & $\mathrm{kWh/a}$ & $12^{\prime} 679$ & $16^{\prime} 679$ & $10^{\prime} 859$ & $\begin{array}{l}\text { Solar electricity to } \\
\text { grid }\end{array}$ \\
\hline$E_{*, \text { sys }}$ & $\mathrm{kWh} / \mathrm{a}$ & $18^{\prime} 377$ & $14^{\prime} 471$ & $15^{\prime} 182$ & $\begin{array}{l}\text { Electricity to heating } \\
\text { system }\end{array}$ \\
\hline$E_{\text {grid,sys }}$ & $\mathrm{kWh} / \mathrm{a}$ & $11^{\prime} 309$ & $10^{\prime} 221$ & $12^{\prime} 846$ & $\begin{array}{l}\text { Electricity from grid } \\
\text { to heating system }\end{array}$ \\
\hline$E_{\text {bat,sys }}^{A C}$ & $\mathrm{kWh} / \mathrm{a}$ & $2^{\prime} 745$ & - & $\begin{array}{l}\text { Electricity from } \\
\text { battery to heating } \\
\text { system }\end{array}$ \\
\hline$E_{*, H P}$ & $\mathrm{kWh} / \mathrm{a}$ & $15^{\prime} 844$ & $12^{\prime} 201$ & $13^{\prime} 301$ & Electricity to HP \\
\hline
\end{tabular}




\section{Application example 2 - Simulation study comparing PVT \& PV with Thermal collectors \& PV}

In a Swiss research project, the performance potential of high-performance covered PVT collectors was investigated. More precisely, for a given building, the performance of such PVT collectors combined with PV modules was compared with the performance of solar flat plate collectors combined with PV modules. In the following sections, we show how some of the KPI's defined above allow to assess the different system variants for the case of a multi-family house. For more details, we refer to the final project report (Zenhäusern, Brunold, and Voirol 2021).

\subsection{System description}

The object studied is a modern multifamily-house in the climate conditions of Zürich (see Figure 9). The heating demand of the building was calculated with the software IDA ICE. ${ }^{14}$ Realistic hot water and household electricity consumption profiles were generated with the software Load Profile Generator. ${ }^{15}$ Table 4 shows the most relevant characteristics of the studied object.

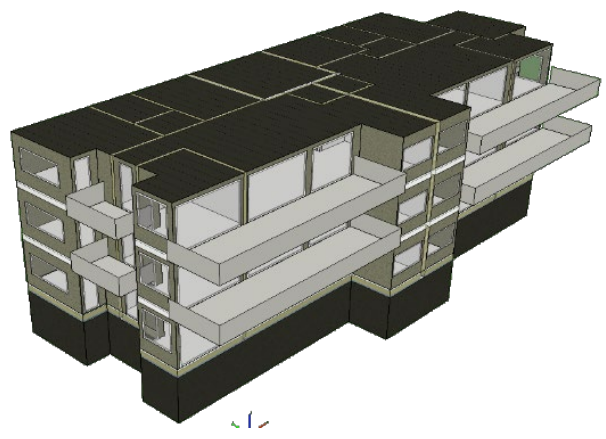

Figure 9: Rendering image of the geometry of the studied building (Mojic et al. 2019).

Table 4: Main characteristics of the building.

\begin{tabular}{|l|l|l|}
\hline Quantity & Units & Value \\
\hline Heated area & $\mathrm{m}^{2}$ & $1 ' 200$ \\
\hline Inhabitants & $\#$ & 18 \\
\hline Gross area of solar energy installation & $\mathrm{m}^{2}$ & $175\left(\right.$ Süd, 30 $\left.{ }^{\circ}\right)$ \\
\hline Space heating demand & $\mathrm{kWh} /\left(\mathrm{m}^{2} \mathrm{a}\right)$ & 29 \\
\hline Hot water demand & $\mathrm{I} /(\mathrm{pd})\left(@ 50^{\circ} \mathrm{C}\right)$ & 57 \\
\hline Total heat demand $Q_{\text {use }}$ & $\mathrm{kWh} / \mathrm{a}$ & $53^{\prime} 055$ \\
\hline Household electricity demand $E_{H E}$ & $\mathrm{kWh} / \mathrm{a}$ & $16^{\prime} 163$ \\
\hline
\end{tabular}

Simulations were carried out with the Software Polysun. ${ }^{16}$ The system configuration studied was based on a standard air/water heat pump together with either a combination of covered PVT collectors and PV modules (PVT\&PV) or a combination of thermal flat plate collectors (T) and PV modules (T\&PV). For all simulations, the total gross area of the solar energy installation was $175 \mathrm{~m}^{2}$. The proportion taken by PVT collectors or thermal collectors, respectively, was varied from $0 \%$ to $100 \%$. The system design is such that the solar heat is used for both domestic hot water and space heating. The sizes of the heat storages and the capacities of the heat exchangers were scaled with the PVT or the T area, respectively. The assumed specifications of the PVT collectors, thermal collectors (T) and $\mathrm{PV}$ modules are given in Table 5.

\footnotetext{
14 https://www.equa.se/de/ida-ice

$15 \mathrm{https}$ ://www.loadprofilegenerator.de/

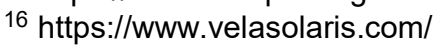


Table 5: Electrical and thermal characteristics of the PVT collectors, thermal collectors and PV modules. The thermal performance coefficients are valid at electrical open circuit operation mode.

\begin{tabular}{|l|c|c|c|c|}
\hline & $\begin{array}{c}\text { Electrical STC efficiency } \\
\text { related to gross area }\end{array}$ & $\eta 0$ & $\begin{array}{c}\mathrm{a}_{1} \\
{\left[\mathrm{~W} /\left(\mathrm{m}^{2} \mathrm{~K}\right)\right]}\end{array}$ & $\begin{array}{c}\mathrm{a}_{2} \\
{\left[\mathrm{~W} /\left(\mathrm{m}^{2} \mathrm{~K}^{2}\right)\right]}\end{array}$ \\
\hline PVT-collector & $15 \%$ & 0.8 & 4.5 & 0.025 \\
\hline Thermal collector & - & 0.85 & 4 & 0.01 \\
\hline PV module & $17.5 \%$ & - & - & - \\
\hline
\end{tabular}

\subsection{Key performance indicators}

The simulation results for the solar yield of the total installation as well as the yield per $\mathrm{m}^{2}$ of solar installation gross area are shown in Figure 10 for the two combinations PVT\&PV and T\&PV, as a function of the proportion of thermally activated area, i.e. of PVT or T, respectively. In this and the subsequent plots, the meaning of the values on the $x$-axis is that the indicated percentage of the total area $(175 \mathrm{~m} 2)$ consists of either PVT or solar thermal collectors, and the rest of the area consists of PV modules. Clearly, a pure PV system ( $0 \%$ i.e. $\left.175 \mathrm{~m}^{2} \mathrm{PV}\right)$ has the highest electrical yield. Replacing PV panels by thermal collectors reduces the electrical yield proportionally to the share of collector area, while replacing PV with PVT only slightly reduces the electrical yield. At a given proportion of PVT or T, the thermal collectors provide more thermal energy, due to their higher thermal efficiency. In all cases, the total solar energy yield is equal or higher for the combination PVT\&PV compared to T\&PV, meaning that PVT\&PV generates more useful energy out of the available roof area.

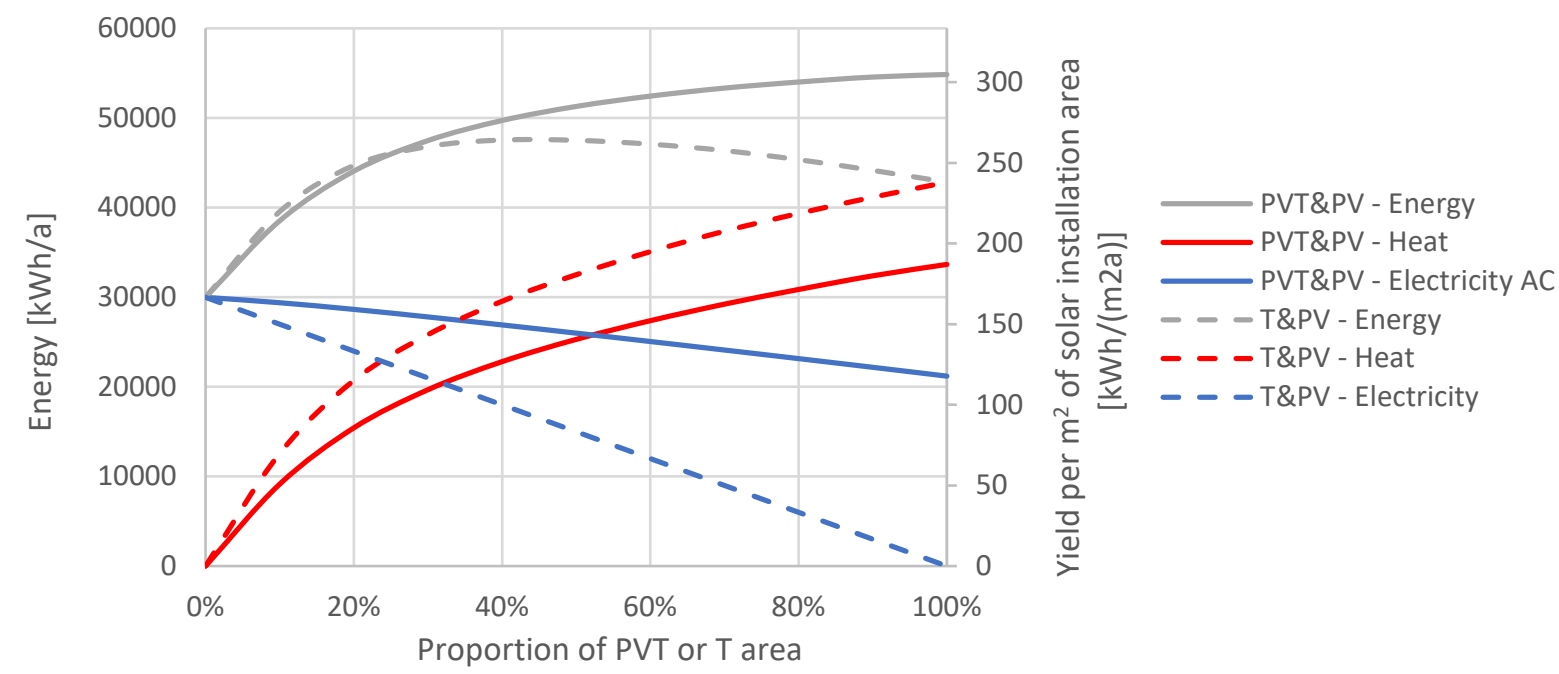

Figure 10: Solar thermal, electrical, and energy yields.

The local solar fractions (thermal $f_{\text {sol,th }}$, electrical $f_{\text {sol,el }}^{(\text {sitelocal) }}$, and energy-related $f_{\text {sol,en }}^{(\text {sitelocal) }}$ ) are shown in Figure 11. For the combination PVT\&PV, the solar electrical fraction (i.e. the proportion of the electricity consumption of the site, consisting of the consumption of the heating systems plus household electricity, covered by self-produced electricity) is practically independent of the proportion of PVT. For the combination T\&PV it decreases, as could be expected, with the share of thermal collector area. The solar thermal fraction (proportion of the total amount of heat injected to the storage tanks covered by solar thermal heat) is higher for the combination T\&PV, if the same thermally activated area (PVT or T collectors) is considered. The same is the case for the solar energy fraction. In this picture, the combination T\&PV might seem favourable. However, depending on the context, a high solar electrical fraction might be more valuable than a high solar thermal fraction, in which case PVT\&PV might be advantageous. Moreover, this indicator does not account for the benefit of solar electricity fed into the grid, which as well is higher in the case of PVT\&PV. 


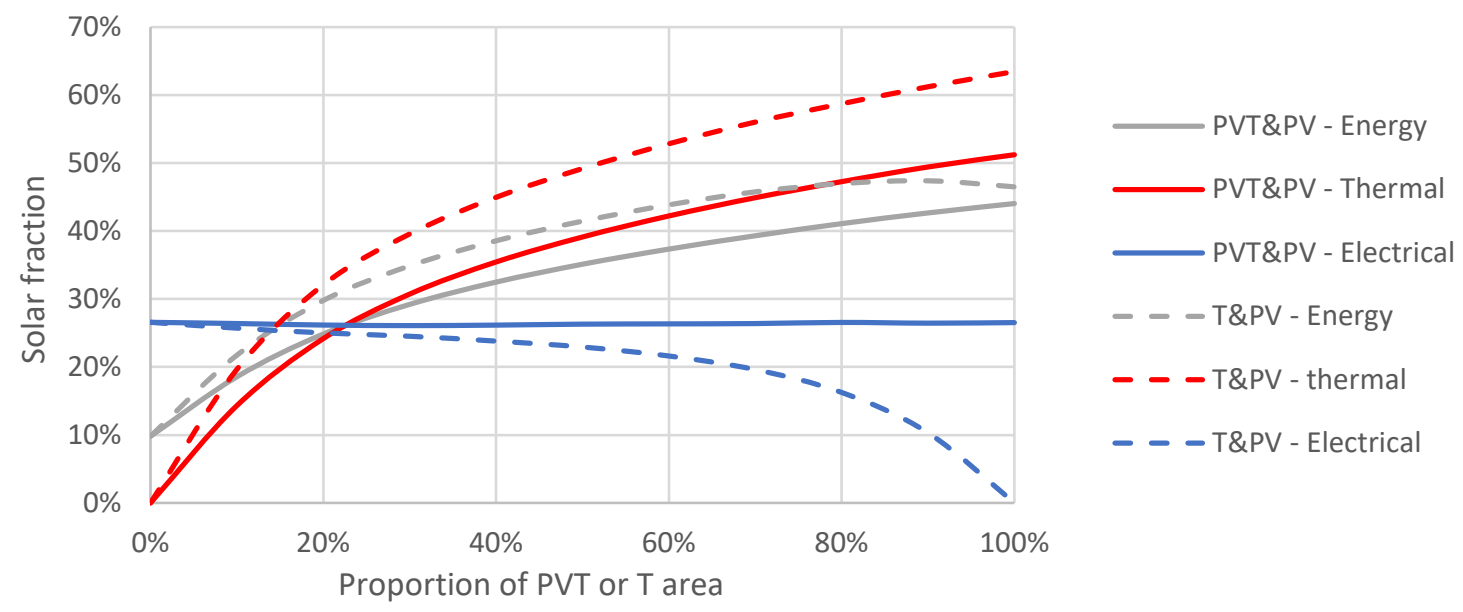

Figure 11: Solar thermal, solar electrical and solar energy fraction.

The seasonal performance factors of the systems are shown in Figure 12, both related to the total electricity consumption of the heating system $S P F_{S H P+}^{(t o t a l)}$, and related to the grid electricity consumed by the heating system, $S P F_{S H P+}^{(\text {Grid })}$. The results reflect that the higher the solar thermal contribution, the higher the SPF that can be reached. The highest value is therefore reached by a pure solar thermal installation, almost 7 compared to below 3 for a system without solar thermal energy components. $S P F_{S H P+}^{(\text {Grid) }}$, which only counts the electricity taken from the grid, is somewhat higher than $S P F_{S H P+}^{(t o t a l)}$. The difference between the two indicators is bigger in the case of PVT\&PV, since with this combination a bigger proportion of the electricity consumed by the heating system is covered by locally generated solar electricity. These seasonal performance factors allows to compare the "efficiency" of the heating systems. However, they do not account for the benefit of local solar electricity made available to the households and for solar electricity fed into the grid.

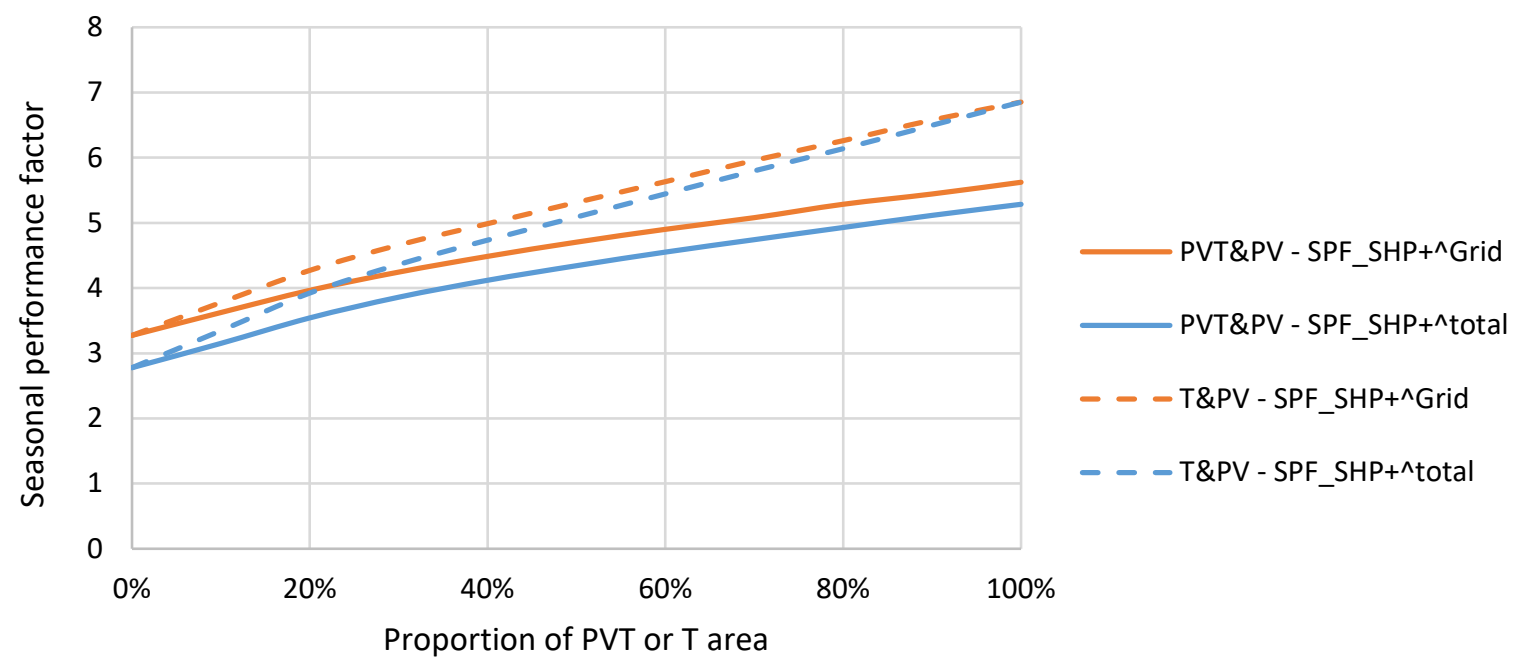

Figure 12: Seasonal performance factors of the systems.

If one is interested in the benefit of the solar energy installation for the whole building, the grid electricity consumption of the site $E_{\text {Grid,site }}$ (including the heating system and household electricity) and the surplus solar electricity fed into the grid $E_{P V T / P V}^{A C}$, Grid are good indicators to look at (see Figure 13). The results show that the possible reduction of grid electricity consumption is slightly bigger in the case of PVT\&PV. The grid electricity consumption of the site without solar energy installation (taken to be the reference system) would be 35 ' $240 \mathrm{kWh} / \mathrm{a}$. Compared to this reference system, the maximum achievable final energy savings $F E_{\text {sav, srid electricity }}^{\text {site }}$ (equivalent to grid electricity consumption savings) amount to 15 '980 kWh/a for PVT\&PV and 14'890 kWh/a for T\&PV, 
corresponding to fractional final energy (or grid electricity) savings of the site $f_{\text {sav,grid electricity }}^{\text {site }} 45 \%$ and $42 \%$, respectively. The achievable savings are therefore similar in the two cases. The combination PVT\&PV, though, has the additional benefit of generating much more solar electricity that can be fed into the grid and substitute final energy consumption elsewhere. Based on the indicators "final energy savings" and "electricity fed into the grid", which reflect the performance of the complete site, the combination PVT\&PV is therefore clearly favourable from an energy point of view.

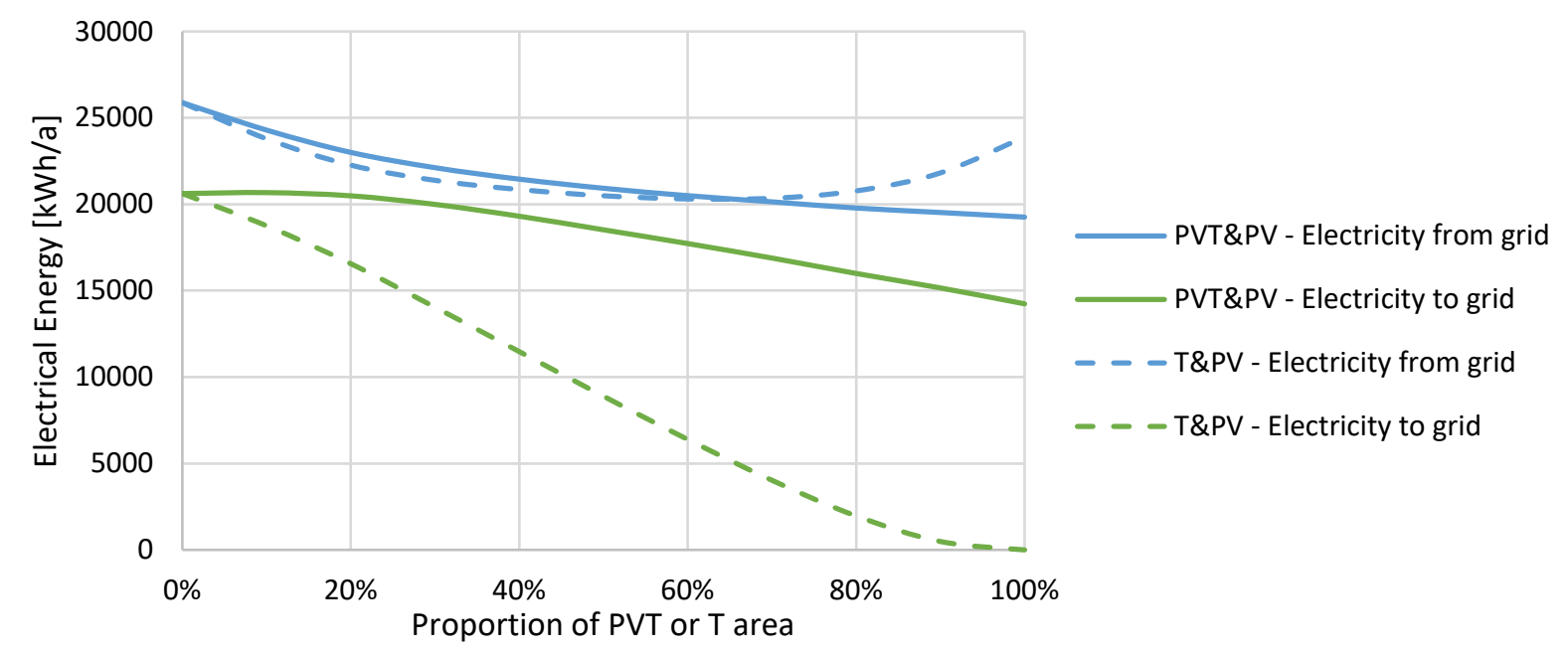

Figure 13: Electricity exchanged between the electricity grid and the building.

In addition to the above energetic considerations, we also want to do a rough assessment of the economic performance. Assuming a retail price of $P_{\text {el. retail }}=0.2 \mathrm{CHF} / \mathrm{kWh}$ for grid electricity and a feed-in tariff of $P_{\text {el. } \text { wholesale }}=0.05 \mathrm{CHF} / \mathrm{kWh}$, one can calculate the net electricity costs, i.e. the costs for purchased grid electricity minus earnings for electricity fed to the grid (see Figure 14). The assumptions are for the Swiss context and the values are given in Swiss Francs (1 CHF $\simeq 0.94$ EUR). The electricity costs of a system without solar installation would be 7'050 CHF/a. With the combination PVT\&PV the yearly costs can be reduced (financial savings $F S_{t}$ ) by at most 3'910 CHF/a and with the combination T\&PV by at most 3'470 CHF/a.

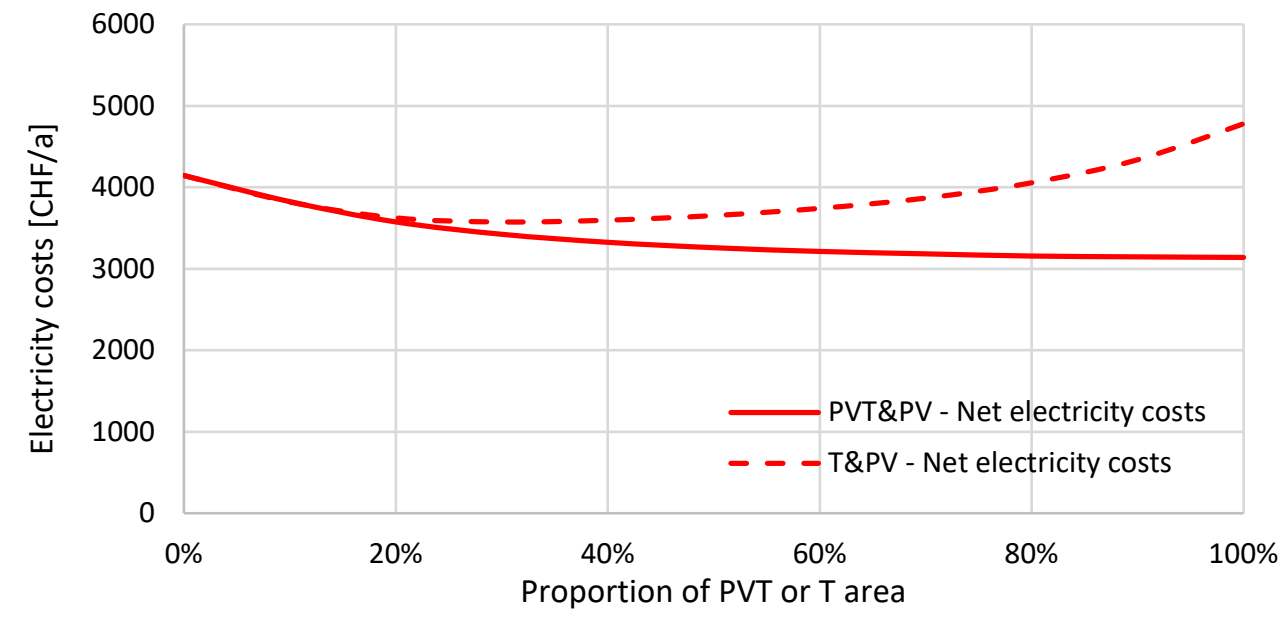

Figure 14: Net electricity costs.

The assumed investment costs per square meter of gross area $i_{0}^{P V T / P V / T}$, including all system components for a PVT, PV, or T system, are shown in Figure 15, as a function of the gross area of the respective system. These assumptions are valid for the Swiss context. 


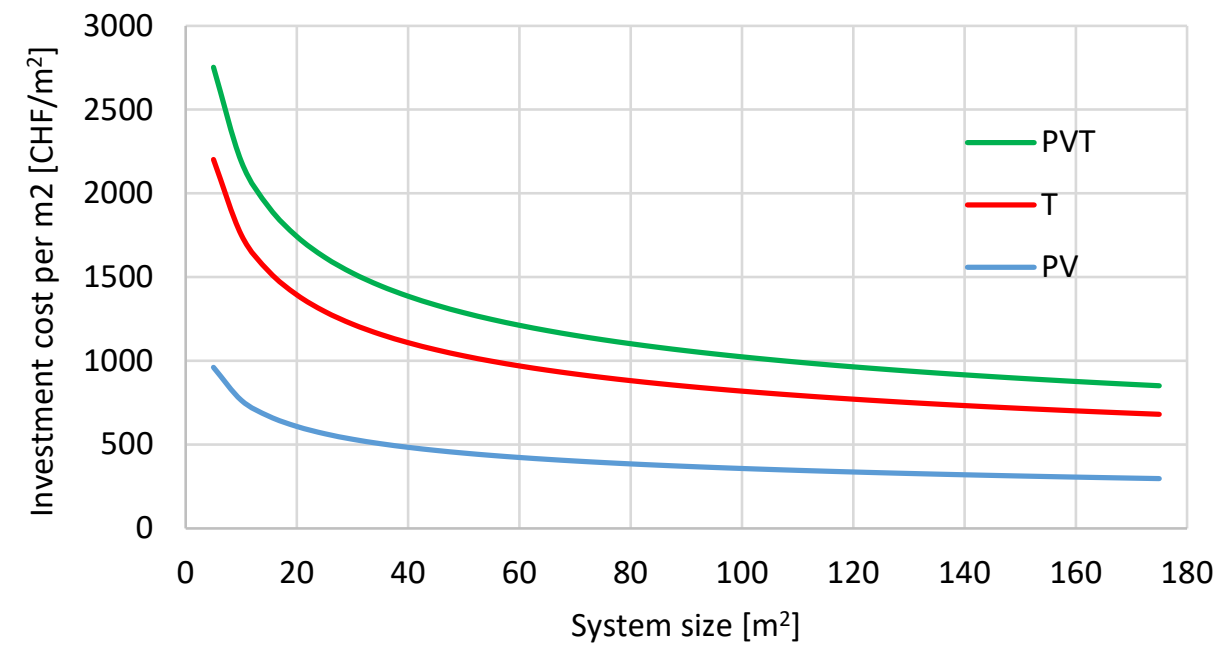

Figure 15: Initial investment cost per $m^{2}$ of PVT, PV, or $T$ (flat plate collector) area as a function of the size of the installation.

In order to roughly assess the investment in a solar installation, one can now look at the levelised costs of energy LCOEn, which combine the investment costs $i_{0}$ and the yearly financial savings $F S_{t}$. More precisely, in the present example, it was decided to rather look at the increase or decrease of the levelised costs of energy as compared to a system without solar energy, i.e. at the quantity $\Delta$ LCOEn. This has the advantage, that only the additional investment costs for the solar energy system need to be known, but not the costs of the basic heat pump system. $\Delta$ LCOEn was calculated as follows

$$
\Delta L C O E n=\frac{A_{\text {gross }}^{P V T} \cdot i_{0}^{P V T}+A_{\text {gross }}^{T} \cdot i_{0}^{T}+A_{\text {gross }}^{P V} \cdot i_{0}^{P V}-\sum_{t=1}^{30} F S_{t} \cdot(1+r)^{-t}}{\sum_{t=1}^{30}\left(Q_{u s e, t}+E_{H E, t}\right) \cdot(1+r)^{-t}},
$$

with an assumed real interest rate $r=1 \%$ and a system lifetime of 30 years. The results are shown in Figure 16.

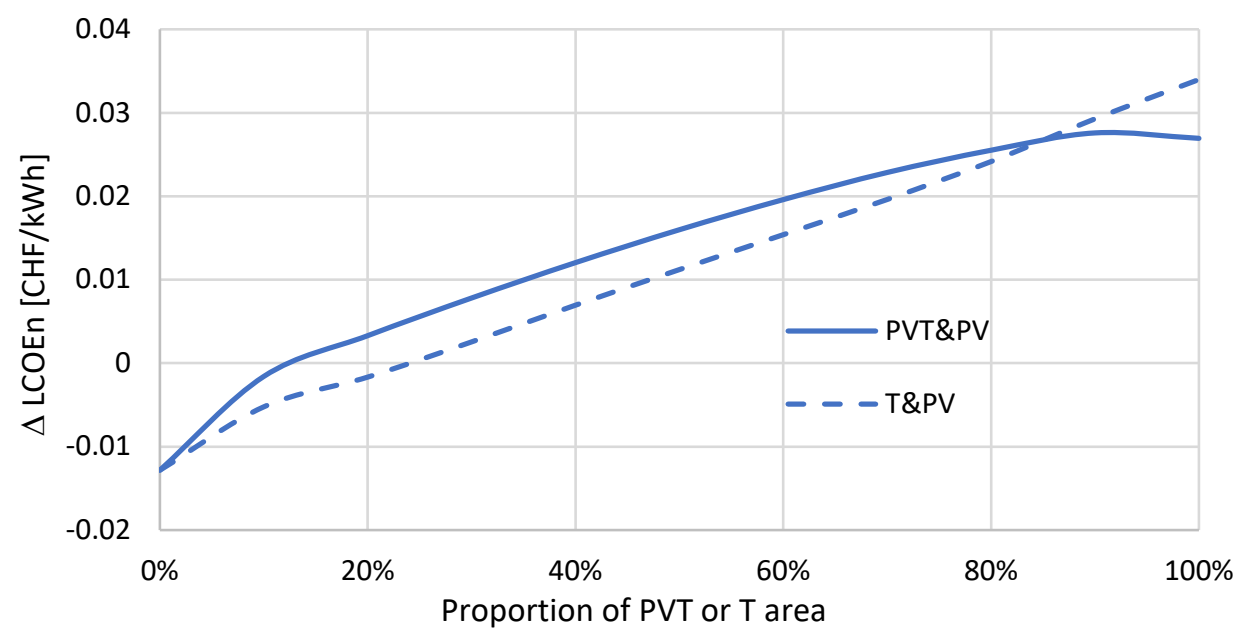

Figure 16: Difference in levelised costs of energy compared to a system without solar energy installation.

The results show that with the given assumptions, only very small proportions of PVT or T result in a negative $\Delta \mathrm{LCOEn}$ and hence a reduction of the levelised costs of energy compared to a system without solar installation. Such configurations are hence favourable from a pure economic point of view. However, as shown above, higher shares of PVT or T can reach considerably higher reductions of the grid electricity consumption, which can be an important benefit for the electricity grid. The results show that this can be reached with only a moderate increase of the levelised costs of energy of about $0.02 \mathrm{CHF} / \mathrm{kWh}$. Possible subsidies, which were not considered in this calculation, could further improve the economic viability. 


\section{Conclusions}

This report contains precise definitions of key performance indicators (KPI's) for PVT-Systems. The members of Task 60, including both scientists and industry representatives, have agreed on the high relevance of these KPI's for the assessment of PVT systems and their comparison with other technologies. On top of the definitions, the report includes two examples showing the applicability and usefulness of the KPI's both to measurement data and simulation results.

This work is original and can pave the way to the definition of a standard if the normative bodies handle the task and the duty to help the customers to compare PVT installations among them and with other technologies, and the manufacturers to target best value proposals.

\section{Bibliography}

Frank, E., M. Haller, S. Herkel, and J. Ruschenburg. 2010. 'Systematic Classification of Combined Solar Thermal and Heat Pump Systems'. In Proc. of the EuroSun 2010 Conference. Graz, Austria.

Frischknecht, Rolf, Niels Jungbluth, H-J Althaus, Roland Hischier, Gabor Doka, Ch Bauer, R Dones, Thomas Nemecek, S Hellweg, and S Humbert. 2007. 'Implementation of Life Cycle Impact Assessment Methods. Data v2. 0 (2007). Ecoinvent Report No. 3'. Ecoinvent Centre.

Hadorn, J.C., ed. 2015. Solar and Heat Pump Systems for Residential Buildings. Solar Heating and Cooling. Wiley. https://books.google.ch/books?id=ALoOCgAAQBAJ.

Herrando, María, Alba Ramos, and Ignacio Zabalza. 2018. 'Cost Competitiveness of a Novel PVT-Based Solar Combined Heating and Power System: Influence of Economic Parameters and Financial Incentives'. Energy Conversion and Management 166 (June): 758-70. https://doi.org/10.1016/j.enconman.2018.04.005.

Koordinationskonferenz der Bau- und Liegenschaftsorgane der öffentlichen Bauherren KBOB, ed. 2016. 'Ökobilanzdaten Im Baubereich 2009/1:2016'. https://www.kbob.admin.ch/kbob/de/home/publikationen/nachhaltigesbauen/oekobilanzdaten_baubereich.html.

Lämmle, Manuel, Axel Oliva, Michael Hermann, Korbinian Kramer, and Wolfgang Kramer. 2017. 'PVT Collector Technologies in Solar Thermal Systems: A Systematic Assessment of Electrical and Thermal Yields with the Novel Characteristic Temperature Approach'. Solar Energy 155 (October): 867-79. https://doi.org/10.1016/j.solener.2017.07.015.

Mojic, Igor, Sascha Crameri, Marco Caflisch, Dani Carbonell, and Michel Haller. 2019. 'Reference Framework for Building and System Simulations: Multifamily Reference Building'. SPF Institut für Solartechnik, HSR Hochschule für Technik Rapperswil.

Sommerfeldt, N., and H. Madani. 2018. 'A Techno-Economic Comparison between PV and PVT Integrated Ground Source Heat Pumps for Multi-Family Houses'. In . Rapperswil, Switzerland.

Stocker, Thomas, ed. 2014. Climate Change 2013: The Physical Science Basis: Working Group I Contribution to the Fifth Assessment Report of the Intergovernmental Panel on Climate Change. Cambridge University Press.

Vassella, C., W. Logie, A. Baggenstos, and D. Zenhäusern. 2020. 'Drei Unterschiedliche Innovative Solarunterstützte Wärmeerzeugungssysteme Für Drei Identische Minergie A-Gebäude'. Schlussbericht BFE Pilot- und Demonstrationsprojekt. Poschiavo.

Wang, Kai, María Herrando, Antonio M. Pantaleo, and Christos N. Markides. 2019. 'Technoeconomic Assessments of Hybrid Photovoltaic-Thermal vs. Conventional Solar-Energy Systems: Case Studies in Heat and Power Provision to Sports Centres'. Applied Energy 254 (November): 113657. https://doi.org/10.1016/j.apenergy.2019.113657.

Zenhäusern, D., S. Brunold, and A. Voirol. 2021. 'HiPer-PVT - Abgedeckter PVT-Kollektor Mit Überhitzungsschutz'. BFE Schlussbericht - to be published in 2021. 